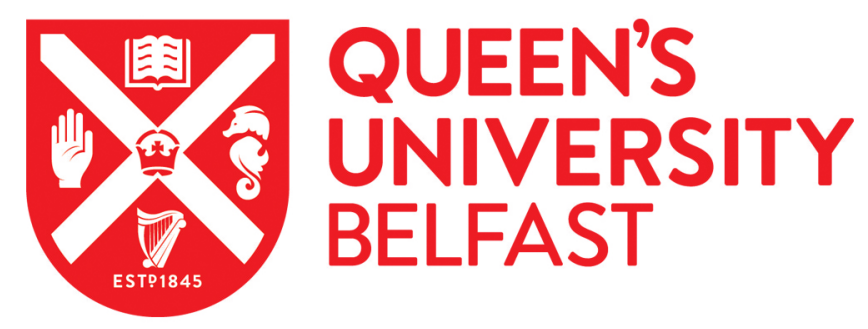

\title{
Enhanced selectivity, cellular uptake, and in vitro activity of an intrinsically fluorescent copper-tirapazamine nanocomplex for hypoxia targeted therapy in prostate cancer
}

Silva, V. L., Kaassis, A., Dehsorkhi, A., Koffi, C-R., Severic, M., Abdelhamid, M., Nyimanu, D., Morris, C. J., \& AlJamal, W. T. (2020). Enhanced selectivity, cellular uptake, and in vitro activity of an intrinsically fluorescent copper-tirapazamine nanocomplex for hypoxia targeted therapy in prostate cancer. Biomaterials science. https://doi.org/10.1039/c9bm01905g

\section{Published in:}

Biomaterials science

\section{Document Version:}

Peer reviewed version

Queen's University Belfast - Research Portal:

Link to publication record in Queen's University Belfast Research Portal

\section{Publisher rights}

Copyright 2020 Royal Society of Chemistry. This work is made available online in accordance with the publisher's policies. Please refer to any applicable terms of use of the publisher.

\section{General rights}

Copyright for the publications made accessible via the Queen's University Belfast Research Portal is retained by the author(s) and / or other copyright owners and it is a condition of accessing these publications that users recognise and abide by the legal requirements associated with these rights.

Take down policy

The Research Portal is Queen's institutional repository that provides access to Queen's research output. Every effort has been made to ensure that content in the Research Portal does not infringe any person's rights, or applicable UK laws. If you discover content in the Research Portal that you believe breaches copyright or violates any law, please contact openaccess@qub.ac.uk. 


\title{
Enhanced selectivity, cellular uptake, and in vitro activity of an intrinsically fluorescent copper-tirapazamine nanocomplex for hypoxia targeted therapy in prostate cancer
}

Vera L. Silva ${ }^{1}$, Abdessamad Kaassis ${ }^{1,2}$, Ashkan Dehsorkhi ${ }^{1}$, Cédrik-Roland Koffi ${ }^{2}$, Maja Severic ${ }^{2}$, Moustafa Abdelhamid ${ }^{1}$, Duuamene Nyimanu ${ }^{1,3}$, Christopher J. Morris ${ }^{1}$, and Wafa' T. Al-Jamal ${ }^{1,2^{*}}$

${ }^{1}$ School of Pharmacy - University of East Anglia, Norwich Research Park, Norwich, NR4 7TJ, United Kingdom

${ }^{2}$ School of Pharmacy - Queen's University Belfast, Belfast, BT9 7BL, United Kingdom.

${ }^{3}$ Experimental Medicine and Immunotherapeutics, University of Cambridge, Centre for Clinical Investigation, Addenbrooke's Hospital, Cambridge, CB2 OQQ, United Kingdom.

*Corresponding author

Dr Wafa' T. Al-Jamal

School of Pharmacy

Queen's University Belfast

Belfast, BT9 7BL, United Kingdom

E-mail: w.al-jamal@qub.ac.uk

\begin{abstract}
In the present work, a copper-tirapazamine (TPZ) nanocomplex $\left[\mathrm{Cu}(\mathrm{TPZ})_{2}\right]$ was synthesized as a selective hypoxia-targeted therapy. The nanocomplex revealed a crystalline form, and exhibited higher lipophilicity, compared to TPZ. Furthermore, its stability was confirmed in different media, with minimum dissociation in serum ( $20 \%$ up to $72 \mathrm{~h}$ ). In contrast to other hypoxia-targeted agents, our intrinsically fluorescent nanocomplex offered an invaluable tool to monitor its cellular uptake and intracellular distribution under both normoxia and hypoxia. The conferred higher cellular uptake of the nanocomplex, especially under hypoxia, and its biocompatible reductive potential resulted in superior hypoxia selectivity in two prostate cancer (PC) cell lines. More promisingly, the nanocomplex showed higher potency in three-dimensional tumor spheroids, compared to TPZ, due to its slower metabolism, and probably deeper penetration in tumor spheroids. Interestingly, the nuclear localization of the intact nanocomplex, combined with its higher DNA binding affinity, as evidenced by the DNA binding assay, resulted in significant S- phase cell-cycle arrest, followed by apoptosis in three-dimensional spheroids model. In conclusion, the presented findings suggested that $\mathrm{Cu}(\mathrm{TPZ})_{2}$ nanocomplex can be a promising hypoxia-targeted therapeutic, which could potentiate the efficacy of existing chemo- and radiotherapy in PC.
\end{abstract}




\section{Introduction}

2 Bio-reductive hypoxic activated pro-drugs (HAP) have been 3 widely exploited as selective cytotoxic compounds, driven by 4 low oxygen conditions, showing promise as novel cancer 5 therapeutics 1,2 . Several $N$-oxide compounds have been 6 proposed as potential candidates, with some progressing into 7 clinical trials. Of particular interest is the hypoxic cytotoxin 3 8 amino-1, 2, 4-benzotriazine-1, 4-dioxide (tirapazamine - TPZ) 9 which exhibits 30-300 times higher toxicity to cells in low oxygen 10 conditions, compared to other cytotoxic agents ${ }^{3-5}$. TPZ is the 11 most advanced bioreductive pro-drug in clinical trials, owing to 12 its one-electron reduction pathway, and hypoxia selective DNA 13 damaging action ${ }^{3}$. Nonetheless, its clinical efficacy has been 14 limited by its poor cellular uptake, restricted tissue diffusion and 15 rapid metabolism ${ }^{4}$.

16 Copper has attracted special attention over the last years as a 17 promising metal coordinate to target cancer hypoxia. The low 18 molecular weight, lipophilicity and planar structure of its 19 complexes allow rapid cellular internalization and targeting of 20 hypoxia 6,7 . It also possesses unique properties conferred by the 21 variety of coordination geometries, metal-ligand interactions 22 and redox activity that allows functionalization of ligands and 23 effective cellular targeting (DNA, proteins, enzymes and redox 24 pathways) ${ }^{8}$. Its unique electronic structure, and cell compatible 25 reduction potential $\left(\mathrm{EO}^{\prime}\left(\mathrm{Cu}^{2+/} \mathrm{Cu}^{+}\right)\right.$allows it to play a 26 fundamental role in cellular growth and proliferation ${ }^{9}$. The 27 coordination of metal ions to hypoxic cytotoxins is an interesting 28 strategy to develop novel hypoxia-targeted therapeutics. These 29 complexes have been exploited therapeutically with different 30 organic ligands ${ }^{9}$, and in radiodiagnosis or radiotherapy ${ }^{10}$. 31 Extensive work by J. Dearling, J. Holland and J. Dilworth has 32 provided detailed analysis on the therapeutic and hypoxia 33 imaging applications of copper-complexes ${ }^{7,9-11}$.

34

35 Copper-based complexes have now been widely exploited for 36 anti-cancer therapy, and their potential thoroughly reviewed 37 elsewhere ${ }^{12}$. Most of these complexes presented improved 38 chemical characteristics compared to the free ligand, 39 contributing to their increased hypoxic uptake, thus more 40 selective and/or potent biological activity 11, 13-15. Particular 41 attention has been drawn to $\mathrm{Cu}(\mathrm{II})$ complexes including $\mathrm{N}, \mathrm{N}$ 42 diimine ligands, thiosemicarbazones, bis(thiosemicarbazones), 43 schiff base assemblies and pyridine- $N$-oxides and their ability to 44 induce DNA damage, via binding or intercalation ${ }^{12}$. Although 45 this is the primary mechanism of action, new cellular targets 46 such as DNA topoisomerases ${ }^{16}$, the proteasome complex ${ }^{17,18}$, 47 endoplasmic reticulum ${ }^{19}$ and lysosome ${ }^{20}$, have also become 48 interesting pathways of cell death for copper-complex mediated 49 therapeutics, highlighting the versatility and potency of these 50 metal therapeutics.

51

52 Lin and Ho ${ }^{21}$ were the first to demonstrate the potential use of 53 TPZ with copper to enhance DNA damaging in cancer cells. Next, 54 they prepared a radioactive TPZ-copper complex for targeted 55 cancer therapy 22. These studies did not report the basic 56 characterization of the complex, which, in our opinion, is 57 considered essential to further understand its biological
58 relevance. Furthermore, data regarding its potential use as a 59 hypoxia cytotoxic agent in more complexed hypoxia models is 60 still warranted. In the present work, we aimed to synthesize and 61 characterize a cupric-TPZ complex (abbreviated in the text as $62 \mathrm{Cu}(\mathrm{TPZ}) 2)$. We sought to understand how complexation with 63 copper could modulate TPZ's physicochemical properties (e.g, 64 optical properties, solubility, and lipophilicity), and its biological 65 activity. Ideally, this Cu(TPZ)2 complex should maintain or 66 improve TPZ hypoxia selectivity and potency while providing an 67 innovative metal-complex strategy for hypoxia therapeutics. 68 Therefore, it was essential to determine the selectivity and 69 potency of this complex vs TPZ alone. Using both 2-dimensional 70 (2D), and 3-dimensional (3D) prostate cancer models, the 71 uptake and cytotoxicity of $\mathrm{Cu}(\mathrm{TPZ}) 2$ was determined in this 72 study. Overall, $\mathrm{Cu}(\mathrm{TPZ}) 2$ complex should overcome some of the $73 \mathrm{TPZ}$ shortcomings in vitro, which could potentiate the efficacy of 74 existing chemo- and radiotherapy in vivo.

75

\section{Experimental}

\section{Materials}

78 4-(2 Hydroxyethyl)piperazine-1-ethanesulfonic acid (HEPES), 79 sodium chloride $(\mathrm{NaCl})$, phosphate buffer saline (PBS) tablets, 80 tirapazamine ( $\geq 98 \% \mathrm{HPLC}$ ), copper(II) chloride (97\%), methanol 81 (HPLC grade) and Universal MALDI Matrix [1:1, 2,582 dihydroxybenzoic acid (DHB): $\alpha$-cyano-4-hydrocinnamic acid] 83 were obtained from Sigma (UK). Laboratory reagent dimethyl 84 sulfoxide (DMSO), chloroform (HPLC grade, stabilized with 85 amylene), methanol (HPLC grade), and ethanol (absolute, 86 99.8\%) were bought from Thermo Fisher Scientific (UK). Milli-Q 87 water was prepared using a water purification system (Millipore 88 Corp., Bedford, MA, USA). All organic solvents were of analytical 89 grade, unless otherwise stated. All starting materials were 90 commercially available research grade chemicals and were used 91 without further purification.

\section{Preparation of $\mathrm{Cu}(\mathrm{TPZ})_{2}$ complexes}

93 Two equivalents of TPZ $(13.2 \mathrm{mg}, 0.074 \mathrm{mmol})$ were added 94 slowly to a total of $5 \mathrm{~mL}$ stirred ethanolic solution of $\mathrm{CuCl}_{2}(5 \mathrm{mg}$, $950.037 \mathrm{mmol})$, resulting in the formation of a deep red 96 precipitate. Following overnight stirring, the dark red precipitate 97 was isolated, and washed with small volumes of ethanol by 98 centrifugation at $5000 \times \mathrm{xg}$ for $10 \mathrm{~min}$, until a colorless 99 supernatant was obtained. The red complex was then left to dry 100 under vacuum at $25^{\circ} \mathrm{C}$, and resuspended in DMSO until 101 complete solubility was obtained ( $2.5 \mathrm{mM}$ stock solution). The 102 complex was then sterile filtered through $0.2 \mu \mathrm{m}$ membrane 103 filter. The stoichiometry of the compound was [ $\left.\mathrm{Cu}(\mathrm{TPZ})_{2}\right]$, and 104 the yield $70 \%$ (11 mg, $0.026 \mathrm{mmol})$. The results of the 105 elemental analysis (\%) obtained with a Carlo Erba EA 1108 106 analyzer were: $\left(\mathrm{C}_{14} \mathrm{H}_{10} \mathrm{CuN}_{8} \mathrm{O}_{4}\right)$ Found/Calcd.: $\mathrm{C}, 39.85 / 40.32 ; \mathrm{N}$, 107 25.66/26.87; $\mathrm{H}, 2.39 / 2.21$. IR (ATR) analysis: $\left(\mathrm{v} / \mathrm{cm}^{-1}\right)-\left({ }_{v} \mathrm{~N}-\mathrm{H}_{2}\right)$, 108 3360-3311; $\left({ }_{\delta} \mathrm{N}-\mathrm{H}_{2}\right), 1570 ;\left({ }_{\mathrm{v}} \mathrm{N} \rightarrow\right.$ O), 1358; $\left({ }_{\mathrm{V}} \mathrm{C}-\mathrm{N} / \mathrm{v} \mathrm{C}-\mathrm{C}\right), 1111$, 109 1165, 1215. MALDI-MS: m/z (\%) [Cu(TPZ) $2-\mathrm{H}]^{+}$, Found/Calcd (\%): 110 418.0199/418.0202 (100). Full details of TPZ and Cu(TPZ) 111 characterization can be found in the experimental section of the 112 supplementary information.

113 


\section{Biological studies}

115 In vitro cytotoxicity of TPZ and $\mathrm{Cu}(\mathrm{TPZ})_{2}$ complex in PCa 116 monolayers

117 LNCap (CRL-1740 ${ }^{\mathrm{TM}}$ ) and C4-2B cells were purchased from ATCC ${ }^{\circledR}$ 118 and MD Anderson Cancer Center (Texas, USA), respectively. The 119 cells were maintained in Advanced RPMI-1640 (1x) medium 120 supplemented with $10 \%$ heat inactivated FBS, $1 \%$ 121 penicillin/streptomycin and 1\% GlutaMax (200 mM). Cells were 122 maintained in Corning ${ }^{\circledR}$ CellBIND $^{\circledR} 75 \mathrm{~cm}^{3}$ canted-neck tissue 123 culture flasks (Fisher Scientific, UK) to enhance cell adherence.

124 For normoxic condition, cell cultures were maintained in a 125 humidified incubator at $37^{\circ} \mathrm{C}$ in $5 \% \mathrm{CO}_{2} / 95 \%$ air. For hypoxia 126 treatment, cells were placed in a hypoxic chamber (Incubator 127 chamber Billups Rothenberg Inc., MIC-101) with a mixture of $1 \%$ $128 \mathrm{O}_{2}, 5 \% \mathrm{CO}_{2}$, and $94 \% \mathrm{~N}_{2}$ (BOC, UK). Hypoxia was validated using 129 the CYTO-ID $^{\circledR}$ Hypoxia/Oxidative Stress Detection kit (Enzo Life 130 Sciences. UK) according to the manufacturer manual ${ }^{23}$.

131

132 Cell culture media and drug stock solutions were pre-purged 133 with the hypoxic gas mixture to minimize oxygen fluctuations. 134 The cytotoxicity of TPZ and Cu(TPZ) ${ }_{2}$ was determined using the 135 resazurin assay, as previously described ${ }^{24}$. Resorufin 136 fluorescence intensity (FI) was measured using a BMG 137 microplate reader (FLUOstar Omega, BMG Labtec) at $544 \mathrm{~nm}$ 138 excitation and $590 \mathrm{~nm}$ emission. The average percentage cell 139 viability was calculated by normalizing the values to the 140 untreated cells, using the following formula:

141

142

$$
\text { Cell Viability }(\%)=\frac{\mathrm{Fl}_{\mathrm{I} \text { trated }}}{\mathrm{F}_{\text {control }}} \times 100
$$

\section{Uptake and cellular localization of TPZ and $\mathrm{Cu}(\mathrm{TPZ})_{2}$ complex}

144 For quantitative uptake studies, confluent C4-2B cells were 145 harvested by trypsinization and seeded onto pre-coated poly-D146 lysine $(100 \mu \mathrm{g} / \mathrm{mL}) 24$ flat-bottom well plates (Triplered, UK) at $1475 \times 10^{4}$ cells/well. The cells were incubated overnight under 148 either normoxia or hypoxia to allow adherence. Next, cells were 149 incubated with free TPZ or its complex (100 $\mu \mathrm{M}$ equivalent TPZ) 150 at $37^{\circ} \mathrm{C}$ for $1,4,8$ and $24 \mathrm{~h}$ to assess uptake. At specific time 151 periods, the medium was removed and the wells were washed 152 (3X) with $200 \mu$ l of cold PBS to remove any free drug. After that, 153 cells were harvested by trypsinization and pelleted by 154 centrifugation ( $500 \mathrm{xg}, 10 \mathrm{mins}$ ). The pellet was resupended in $155200 \mu \mathrm{L}$ of DMSO (to guarantee solubility of released drug) and 156 cells were then lysed by mechanical disruption using a bath 157 sonicator for about 15 min (Ultrasound cleaning baths, USC, 158 VWR). This ensured full disruption of cell membrane and 159 intracellular organelles. The fluorescence intensity of each 160 sample well was measured using a microplate reader (FLUOstar 161 Omega, BMG Labtec) at $485 \mathrm{~nm}$ excitation and $590 \mathrm{~nm}$ emission. 162 The percentage of drug uptake was calculated by dividing the 163 fluorescence of each well by the fluorescence of the initial drug 164 concentration used.

165

166 For fluorescence microscopy, C4-2B cells were seeded at $5 \times$ $16710^{4} /$ well onto pre-coated poly-D-lysine $(100 \mu \mathrm{g} / \mathrm{mL})$ Coverslips 168 (Fisher Scientific, UK), placed in 24 well assay plates (Triplered, 169 UK) and left to adhere overnight at $37{ }^{\circ} \mathrm{C}$ under normoxia or 170 hypoxia. Next, the cells were incubated with TPZ or its complex 171 for $1,4,8$ and 24 h, under both normoxia or $1 \%$ hypoxia. Cells
172 were then washed with cold PBS and fixed with 4\% PFA at room 173 temperature for $20 \mathrm{~min}$, then washed (3X) with cold PBS. The 174 nuclei were stained with Hoechst $33258(5 \mathrm{\mu g} / \mathrm{mL}$ ) (Sigma, UK) 175 for $30 \mathrm{~min}$ at $37^{\circ} \mathrm{C}$. Finally, the coverslips were washed $(3 \mathrm{X})$ with 176 PBS, and mounted using ProLong ${ }^{\mathrm{TM}}$ Gold Antifade mounting 177 media (Fisher Scientific, UK). Images were obtained using a Zeiss 178 Axioplan 2 epifluorescence Axiovision 4.1.8 software. Images 179 were processed and analysed using Image $(\mathrm{NIH}$, Bethesda, MD, 180 USA: http://imagej.nih.gov/ij). For each endpoint, duplicates of 181 two independent experiments $(n=2)$ resulted in the analysis of 182 over 50 cells. For some experimental conditions a z-stack with $1831.75 \mu \mathrm{m}$ intervals was generated using the Apotome to form a $1843 \mathrm{D}$ reconstruction and evaluate co-localization via orthogonal 185 projections. All images were acquired with a 10x/0.45 air 186 objective and Axiovision 4.1.8 software, processed and analysed 187 using Image $(\mathrm{NIH}$, Bethesda, MD, USA: 188 http://imagej.nih.gov/ii).

189

\section{Analysis of $\mathrm{Cu}(\mathrm{TPZ})_{2}$ metabolism using FTIR and NMR}

191 C4-2B cells were seeded on pre-coated poly-D-lysine (100 $192 \mu \mathrm{g} / \mathrm{mL}$ ) at $5 \times 10^{4} /$ well in 24 well assay plates (Triplered, UK) and 193 left to adhere overnight at $37^{\circ} \mathrm{C}$ under hypoxia. Next, the cells 194 were incubated with TPZ in its free or complex form $(100 \mu \mathrm{M}$ 195 equivalent TPZ) for $1,4,8$ and $24 \mathrm{~h}$, under $1 \%$ hypoxia using a 196 hypoxic chamber (Ruskinn Invivo 2400 Hypoxia Workstation). At 197 specific time periods, the medium was removed and the wells 198 were washed (3X) with PBS to remove any free drug, and cells 199 were lysed with $200 \mu \mathrm{L}$ of RIPA buffer. Cell lysate samples were 200 stored at $-20^{\circ} \mathrm{C}$ until further FTIR and NMR analysis.

$201200 \mu \mathrm{L}$ of cell lysates was diluted in $200 \mu \mathrm{L} \mathrm{D}_{2} \mathrm{O}$ (Fisher, UK) and 202 probed by nuclear magnetic resonance (NMR). The Spectra were 203 recorded at $297 \mathrm{~K}$, on an ultra-shield 400 instrument $\left({ }^{1} \mathrm{H}\right.$ 204 frequency: $400 \mathrm{MHz}$; Bruker, Germany). Then, all the samples 205 were dried and were dissolved in $400 \mu \mathrm{LCDCl}_{3}$ in presence of 206 Tetramethyl silane (TMS) and run at the same conditions. 207 Finally, the samples were dried and dissolved in DMSO in the 208 presence of TMS. The samples were analyzed using IR 209 spectroscopy (Spectrum Two FTIR, Perkin Elmer, USA) over the 210 range $650-4000 \mathrm{~cm}^{-1}$ with a resolution of $4 \mathrm{~cm}^{-1}$.

\section{In vitro cytotoxicity of TPZ and $\mathrm{Cu}(\mathrm{TPZ})_{2}$ in C4-2B spheroids}

212 C4-2B spheroids were cultured and characterized as described 213 in the supporting information. Five days post spheroid seeding, $214100 \mu \mathrm{L}$ of media was carefully removed and replaced with pre215 diluted fixed concentrations of TPZ in free and complexed form 216 (TPZ equivalent: 0.002 up to $20 \mu \mathrm{M}$ ). Spheroids were treated for 21748,72 and $96 \mathrm{~h}$ using $10 \%$ DMSO as a positive control. Spheroids 218 were carefully washed with PBS $1 x$ and replenished with fresh 219 media or pre-treated with EDTA $(5 \mathrm{mM})$ for $30 \mathrm{~min}$, with shaking $220(70 \mathrm{rpm})$ to ensure resazurin penetration and reliable 221 quantification ${ }^{24}$. Resazurin solution $(20 \mu \mathrm{l})$ was then added to 222 each well and the spheroids were further incubated overnight, 223 at $37^{\circ} \mathrm{C}$ to determine cell viability. To complement the viability 224 assay, representative spheroid images were taken to monitor 225 spheroid size changes before and after treatment. The average 226 percentage cell viability for each drug concentration was 227 expressed as mean \pm S.D of six replicates of three independent 228 experiments ( $\geq 18$ spheroids, $n \geq 2$ ) and calculated by normalizing 229 the Fl values to the untreated cells. Dose-response curves were 230 generated, where possible, and the $I_{50}$ values for drug 231 inhibition were determined by nonlinear regression analysis of 
232 the data fit to a four-parameter equation (GraphPad Prism 233 version 7, La Jolla California USA www.graphpad.com).

\section{Cell cycle and apoptosis analysis using Flow Cytometry}

$235 \mathrm{C} 4-2 \mathrm{~B}$ spheroids were cultured at a density of $5 \times 10^{3}$ cells/well, 236 as described above and on day 5 of growth, were treated with 2 237 and $20 \mu \mathrm{M}$ (equivalent TPZ content) in free and copper238 complexed form. Untreated spheroids were used for 239 population gating to avoid the undesired noises from debris 240 and singlet gating to minimize debris and cell aggregates. 72 $241 \mathrm{~h}$ post-treatment, spheroids were harvested, using a $1 \mathrm{~mL}$ pre242 cut micropipette tip, into $1.5 \mathrm{~mL}$ micro centrifuge tubes (Fisher 243 Scientific, UK) and centrifuged at $500 \times \mathrm{g}$ for $5 \mathrm{~min}$, to sediment 244 the spheroids. The cells were then washed $3 \times$ with cold PBS, 245 with repeated centrifugation and resuspended in $100 \mu \mathrm{L}$ of PBS. 246 Thereafter, a single cell suspension was formed by mechanical 247 dissociation, using a micropipette, and cells were fixed in $70 \%$ 248 ethanol for at least $1 \mathrm{~h}$, on ice. To achieve this, $400 \mu \mathrm{L}$ of ice-cold $24970 \%$ ethanol was added dropwise to each sample, while 250 vortexing to ensure complete fixation and avoid cell clumping. 251 Cells were then washed $3 \times$ with PBS (first spin at $800 \times$ g, 10 min, 252 to recover all cells) and the cell pellet was resuspended in 0.5 $253 \mathrm{~mL}$ of propidium iodide/RNase solution ( $\mathrm{FxCycle}{ }^{\mathrm{TM}}$ Solution, 254 Molecular Probes, UK). The samples were incubated for $30 \mathrm{~min}$ 255 at room temperature, protected from light and further 256 analysed, without washing, by flow cytometry using a Becton 257 Dickinson CytoFLEX (Beckman Coulter, UK). Cell doublets were 258 separated from single cells in $\mathrm{G} 2 / \mathrm{M}$ phase using pulse259 width/pulse-area signal. At least 10,000 cells were acquired in a 260 histogram and cell cycle data were exported as FSC files and 261 analysed using FlowJo software. Each data measurement was 262 made up from at least ten pooled spheroids, repeating the 263 whole procedure independently two times $(n=2)$. Results were 264 expressed as mean \pm S.D, after population deconvolution, peak 265 integration and calculation of population percentage.

\section{DNA binding studies}

267 The interaction between $\mathrm{Cu}(\mathrm{TPZ})_{2}(25 \mu \mathrm{M})$ and calf-thymus DNA 268 (CT-DNA) was analysed by UV/Vis spectroscopy. The CT-DNA 269 stock solution, was prepared in Tris-buffer (containing $5 \mathrm{mM}$ 270 Tris- $\mathrm{HCl}$ and $50 \mathrm{mM} \mathrm{NaCl}$ at $\mathrm{pH}$ 7.2). The UV absorbance at 260 271 and $280 \mathrm{~nm}$ of the CT-DNA gave a ratio of 1.84, indicating that 272 DNA was sufficiently free of protein contamination. DNA stock 273 concentration (8.71 $\mathrm{mM})$ was determined 274 spectrophotometrically at $260 \mathrm{~nm}$, by using the molar extinction 275 coefficient value of $6600 \mathrm{M}^{-1} \mathrm{~cm}^{-1} 25$.

$276 \mathrm{Cu}(\mathrm{TPZ})_{2}(25 \mu \mathrm{M})$ solutions were also prepared in Tris-buffer, 277 where red dispersion was observed, indicating good dispersion 278 of the complex in this buffer. We further performed electronic 279 absorption titrations, which were carried out with a constant 280 concentration of the copper(II) complex $(25 \mu \mathrm{M})$ and varying 281 concentrations of CT-DNA $(0-500 \mu \mathrm{M})$ in Tris-buffer. The 282 complex and DNA solutions were incubated at $37^{\circ} \mathrm{C}$ for $24 \mathrm{~h}$. 283 Subsequently, the spectra were recorded using a UV/Vis 284 spectrophotometer at ambient temperature. Solutions of free 285 CT-DNA (namely in the absence of copper compound) at the 286 corresponding concentrations $(0-500 \mu \mathrm{M})$ were used as blanks 287 before recording the absorption band of each sample. The 288 titrations of the corresponding concentration of TPZ $(50 \mu \mathrm{M})$ 289 were also performed, with varying concentrations of CT-DNA (0$290500 \mu \mathrm{M})$. Solvent samples without DNA or drug were used as 291 baseline references. The results were presented as mean
292 absorbance of triplicate samples of two independent 293 experiments $(n=2)$

294 The intrinsic binding constant $\left(\mathrm{K}_{\mathbf{b}}\right)$ for the interaction of $\mathrm{Cu}(\mathrm{TPZ})_{2}$ 295 with CT-DNA was calculated using the following equation:

$$
\frac{[D N A]}{\varepsilon_{a}-\varepsilon f}=\frac{[D N A]}{\varepsilon b-\varepsilon_{f}}+\frac{1}{K_{b}\left(\varepsilon_{b}-\varepsilon_{f}\right)}
$$

297 where $\varepsilon_{\mathrm{a}}, \varepsilon_{\mathrm{f}}$ and $\varepsilon_{\mathrm{b}}$ correspond to, the apparent molar 298 extinction coefficient - $\mathbf{A}_{\text {obsd }} /[\mathbf{C u}]$, the molar extinction 299 coefficient for the free $\mathrm{Cu}(\mathrm{TPZ})_{2}$, and the molar extinction 300 coefficient for the $\mathrm{Cu}(\mathrm{TPZ})_{2}$ in the fully bound form,

301 respectively. By plotting [DNA]/( $\left.\varepsilon_{a}-\varepsilon_{f}\right) v s$ [DNA], $K_{b}$ was then 302 determined by calculating the ratio of the slope to the 303 intercept.

304

\section{Statistical analysis}

306 Data was presented as mean \pm SD. Two-way Analysis of variance 307 (ANOVA) and Bonferroni multiple comparisons post-hoc test 308 was performed when three or more groups of data were 309 analysed. P-values $<0.05$ were considered significant and 310 statistical differences amongst groups was appropriately 311 denoted in the figure captions. The $I_{50}$ values for inhibition 312 were determined by nonlinear regression analysis of the data fit 313 to a four-parameter equation. All analyses and graphs were 314 generated using GraphPad Prism version 7.0 (GraphPad 315 Software, La Jolla California USA, www.graphpad.com). 316

\section{Results}

\section{$318 \mathrm{Cu}(\mathrm{TPZ})_{2}$ synthesis and characterization}

319 In this study, $\mathrm{Cu}(\mathrm{TPZ})_{2}$ complex was prepared by mixing TPZ with $320 \mathrm{CuCl}_{2}$ salt in an ethanolic solution (Figure. 1A). The red 321 precipitate was collected, and its chemical structure was 322 confirmed using elemental analysis, FTIR (Figure. S1), and mass 323 spectrometry (MS) (Figure. S2). The relevant physicochemical 324 properties (molecular mass, pKa and logP values) of TPZ ${ }^{26}$ and $325 \mathrm{Cu}(\mathrm{TPZ})_{2} 27$ were summarized in Figure. 1B. Based on the 326 literature, $\mathrm{Cu}(\mathrm{TPZ})_{2}$ complex exhibited a biocompatible 327 reductive potential $(-0.75 \mathrm{~V}$ vs. $\mathrm{Ag} / \mathrm{AgCl})$, which was more 328 electronegative than that presented by TPZ $(-0.65 \mathrm{~V} v$ s. $\mathrm{Ag} / \mathrm{AgCl})$, 329 suggesting superior selectivity under hypoxia 10, 19, 20, 28 .

330 The morphology and the structure of the isolated $\mathrm{Cu}(\mathrm{TPZ})_{2}$ 331 complex were also analyzed using TEM and X-ray powder 332 diffraction (XRD), respectively. Due to the higher hydrophobic 333 nature of the complex (solubility $\sim 2.5 \mathrm{mM}$ in DMSO), some 334 intermolecular interactions occurred at high concentrations, 335 resulting in highly organized nanostructures in more polar 336 solvents (e.g. ethanol). Interestingly. TEM examination revealed 337 that the complex morphology was concentration-dependent, 338 where needle-like structures (300-400 nm in length) were 339 present at high concentrations $(2 \mathrm{mM})$, and tiny and 340 homogenous spherical nanoparticles ( $3-4 \mathrm{~nm}$ in diameter) were 341 observed at lower concentrations $(20 \mu \mathrm{M})$ (Figure. 1C), similar 342 to the concentration range used in this study $(20 \mu \mathrm{M})$. The large 343 needle structures possibly result from $\pi \rightarrow \pi$ stacking and van 
344 der Waals interaction between molecules ${ }^{14,17}$, which strongly 345 agrees with the proposed 3D structure (Figure. 1A). Single346 crystal $\mathrm{X}$-ray diffraction measurement was not possible to 347 perform due to the small size of the complex crystals, however, 348 the XRD result confirmed that the complex is in the crystalline 349 form, with the following diffraction reflections 8.3ㅇ, 10.9ㅇ, 35013.4 ㅇ, 15.6ㅇ, 18.9ㅇ, 25.6ㅇ and 28.7ㅇ (Figure. S4). All the complex 351 characterization results are described in detail in the supporting 352 information.

\section{$353 \mathrm{Cu}(\mathrm{TPZ})_{2}$ stability and dissociation in different media}

354 TPZ complexation was further confirmed using UV-Vis 355 spectrophotometry. Both free and complexed TPZ showed 356 similar optical properties in DMSO, with two characteristic 357 absorption peaks at $\lambda_{\max } 280 \mathrm{~nm}$ and $500 \mathrm{~nm}$ (Figure. 1D). In HBS $358 \mathrm{TPZ}$ presented a less intense band at $\lambda_{\max } 280 \mathrm{~nm}$ and a more 359 intense band at $\lambda_{\max } 462 \mathrm{~nm}$ (Figure. 1E), arisen from the $\pi \rightarrow \pi^{*}$ 360 transitions in the phenyl group and $\pi \rightarrow \pi^{*}$ transitions from the 361 pyridine- $N$-Oxide, respectively. $\mathrm{Cu}(\mathrm{TPZ})_{2}$ maintained a ligand 362 centered band at $\lambda_{\max } 280 \mathrm{~nm}$ and a broad absorption band in 363 the visible region at $500-600 \mathrm{~nm}$, which is characteristic for 364 copper (II) $d-d$ transition band (band I: $d_{x y, y z} \rightarrow d_{x 2-y 2}$ ) ${ }^{29}$. The 365 optical properties in different aqueous media were also studied, 366 as described in the supporting information (Figure. S5).

367 To fully understand the dissociation mechanism of the complex, 368 a simple titration study was performed by diluting the formed 369 complex in aqueous buffers with a wide range of $\mathrm{pH}$ (Figure. 1F). 370 An immediate color change was observed by decreasing the $\mathrm{pH}$ 371 from 7.4 to 5 . This was confirmed by a visible shift in the complex 372 absorption ( $555 \mathrm{~nm}$ and $595 \mathrm{~nm}$ ) to a lower wavelength (462 $373 \mathrm{~nm}$ ), indicating the dissociation of the complex at lower $\mathrm{pH}$. A 374 single sigmoidal curve was fitted to the absorbance at $462 \mathrm{~nm}$ 375 and plotted against $\mathrm{pH}$, providing a pKa value of 2.7 (Figure. 376 S5D), comparable to that obtained before for TPZ 27. 377 Furthermore, the stability of the complex was assessed in $50 \%$ 378 serum, where minimum dissociation was evidenced ( $20 \%$ up to 37972 h) (Figure. S6), indicating high stability of the complex under 380 physiological conditions. It is possible that a small number of $381 \mathrm{Cu}(\mathrm{TPZ})_{2}$ molecules could have undergone copper-translocation 382 via serum albumin ${ }^{47}$, leading to free TPZ liberation.

\section{3}

384 Cellular uptake and metabolic analysis of intrinsically 385 fluorescent $\mathrm{Cu}(\mathrm{TPZ})_{2}$ complex

386 Poole et al. previously reported weak fluorescence of TPZ in 387 solutions ${ }^{30}$. This agrees with our findings, where TPZ was 388 fluorescent a wide range of aqueous media (Figure. S7A), except 389 at $\mathrm{pH} 12.5$ (Figure. S7B) ${ }^{30}$. Our current results showed that 390 complexing TPZ to copper did not affect TPZ fluorescence 391 emission in DMSO (Figure 2A, left). On the other hand, a 392 significant enhancement in intensity was observed in HBS buffer $393 \mathrm{pH} 7.4$ (Figure. 2A, right), with a 50-nm red shift upon 394 coordination to the metal center. Interestingly, as the complex 395 dissociated at low $\mathrm{pH}$, a two-fold reduction in the fluorescence 396 intensities was observed, reaching the same level of free TPZ.

397 This strongly indicates that the fluorescent enhancement was 398 metal-induced (Figure. S7C). Despite the strong quenching 399 capacity of $\mathrm{Cu}(\mathrm{II})$, such fluorescence enhancement following 400 copper complexation was previously reported 28 .

\section{1}

402 Encouraged by the intrinsic fluorescence of the complex, and its 403 high serum stability, we further monitored its cellular
404 localization and accumulation under normoxia $\left(21 \% \mathrm{O}_{2}\right)$ and $1 \%$ 405 hypoxia, where the latter was validated using a hypoxia marker 406 (Figure. S8). Representative images were then taken at 1, 4, 8 407 and $24 \mathrm{~h}$ under normoxia (Figure 2B, left) and hypoxia (Figure 408 2B, right), which showed the cellular accumulation of $\mathrm{Cu}(\mathrm{TPZ})_{2}$ 409 (green fluorescence) in C4-2B cells. Interestingly, the results 410 depicted a rapid uptake $(1 \mathrm{~h})$ of the complex, with strong green 411 fluorescent signals in the cytosol and perinuclear region, under 412 both normoxia and 1\% hypoxia. Furthermore, some images 413 evidenced nuclear localization of the intact fluorescent complex, 414 presented as diffuse green signals in the nucleus (Figure 2B) or 415 as punctate signals (Figure. S9). At $4 \mathrm{~h}$, the appearance of bright 416 green punctate structures (depicted by white arrows), 417 particularly in hypoxic conditions, suggested that copper 418 complex can also accumulate in lysosomal compartments or 419 autophagic structures $6,10,11,14$, however, the exact mechanism 420 of the complex internalization should be confirmed. After $8 \mathrm{~h}$, 421 the fluorescent signals were clearly lower, suggesting complex 422 efflux, dissociation or metabolism, as we further confirmed. A 423 slight increase in fluorescence was observed after $24 \mathrm{~h}$, possibly 424 due to reoxidation of a small number of $\mathrm{Cu}(\mathrm{TPZ})_{2}$ molecules via 425 copper recycling pools. Further studies are required to 426 investigate this observation.

427

428 TPZ's weak fluorescence was not reliable to evaluate its cellular 429 uptake and localization under the same conditions (Figure. S10). 430 Therefore, we developed a quantitative method to assess the 431 complex uptake overtime. We compared the total uptake of TPZ 432 and $\mathrm{Cu}(\mathrm{TPZ})_{2}$, up to $24 \mathrm{~h}$, under both normoxia and $1 \%$ hypoxia 433 conditions (Figure. 2C). As evidenced before ${ }^{5}$, TPZ showed low 434 cellular uptake, with no significant differences under both 435 normoxia and hypoxia. On the other hand, $\mathrm{Cu}(\mathrm{TPZ})_{2}$ showed a 436 significant improvement in cellular uptake, under normoxia $(4 \mathrm{~h}$, $437 \mathrm{p}<0.001 ; 8 \mathrm{~h}, \mathrm{p}<0.01$ and $24 \mathrm{~h}, \mathrm{p}<0.0001)$ and hypoxia $(4 \mathrm{~h}$, $438 p<0.0001 ; 8 h, p<0.05$ and $24 h, p<0.0001$ ), compared to TPZ 439 (Figure. 2C). These observations could be attributed to the 440 higher lipophilicity of the complex (LogP 2.88) compared to TPZ 441 (LogP -0.31). More importantly and in line with previous reports $44210,13,14$, the complex demonstrated selective hypoxia uptake at $4434 \mathrm{~h}$ with higher uptake efficiency compared to normoxia ( $\mathrm{p}$ $444<0.001)$. The bioreductive cycle in the lysosome $\left(E_{\text {red }}-0.75\right)$, 445 could be responsible for this high intracellular accumulation, 446 with decreased complex efflux under hypoxia ${ }^{15}$. The full 447 mechanism underlining this hypoxia selectivity is detailed in the 448 discussion section. Furthermore, the slight decrease in cell 449 uptake at $8 \mathrm{~h}$, could be attributed to complex dissociation in 450 acidic compartments, such as lysosomes, with consequent loss 451 of fluorescence intensity, which agrees with the fluorescent 452 imaging and previous results (Figure S7C).

453

454 Drug metabolism could be responsible for the decreased 455 intracellular concentrations of the complex. To verify this, we 456 assessed the metabolism of TPZ and the complex following cell 457 internalization, under hypoxia, using non-fluorescent-based 458 techniques, namely FTIR and NMR. Our qualitative FTIR results, 459 revealed a fast metabolism of TPZ, in contrast to the complex, 460 where free TPZ was metabolized and an intermediate was 461 formed within $1 \mathrm{~h}$ of cell internalization (Figure. S11). This fast $462 \mathrm{TPZ}$ metabolism is in agreement with the literature ${ }^{31}$. On the 463 other hand, neither free TPZ, nor its intermediate metabolite 464 was detected in the cell lysate samples incubated for $1 \mathrm{~h}$ with 465 the complex (Figure. S12), re-emphasising the stability of the 
466 complex intracellularly, and its slow metabolism, respectively. 467 Between 4 and $24 \mathrm{~h}$ similar metabolites were present in all 468 samples. Moreover, as anticipated, the metabolite levels in the 469 TPZ samples were much higher compared to cells incubated 470 with the complex (Figure. 3C), indicating slower metabolism of 471 the complex, as confirmed by NMR. These quantitative results 472 showed that the levels of the complex metabolites, in contrast 473 to free TPZ, fluctuated over time, with the highest level detected 474 after $4 \mathrm{~h}$. The metabolism decreased slightly around $8 \mathrm{~h}$, before 475 increasing again after $24 \mathrm{~h}$ (Figure. 3C). It is worth mentioning 476 that the complex was present in the cell lysate (pellet) samples 477 (Figure. 3B), but could not be detected using NMR, since it was 478 precipitated from the supernatant due to a solubility issue. 479 Interestingly, these results could justify the loss of fluorescence 480 signal at $8 \mathrm{~h}$ (Figure. 2B\& 2C), followed by some signal recovery 481 at $24 \mathrm{~h}$. Several in vitro studies reported TPZ benzotriazine 482 radical and mono- $N$-oxide (SR4317) as major TPZ metabolites ${ }^{32}$, 483 however, in presence of DNA, identifying the exact metabolites 484 becomes more challenging, since the interaction of TPZ 485 benzotriazine radicals with the DNA results in DNA damage, and 486 different products are formed ${ }^{33}$. The latter observation could 487 possibly explain the unreported metabolite peaks detected by 488 NMR (Figure. 3), however, the exact metabolites formed in our 489 study remain to be identified.

490

\section{Hypoxia selectivity of $\mathrm{Cu}(\mathrm{TPZ})_{2}$ complex in PCa cells}

492 To assess hypoxia selectivity, the cytotoxicity of free TPZ and $493 \mathrm{Cu}(\mathrm{TPZ})_{2}$ complex was studied under normoxia $\left(21 \% \mathrm{O}_{2}\right)$ and $1 \%$ 494 hypoxia in two prostate cancer (PCa) cell lines. The inhibitory 495 concentrations $\left(I C_{50}\right)$ were determined under both conditions 496 and used to calculate the hypoxia cytotoxicity ratio (HCR, IC 50 497 normoxia/IC 50 hypoxia), which expresses hypoxia selectivity. 498 The $\mathrm{IC}_{50}$ and HCR values obtained in the PCa cell lines are 499 summarized in Table $\mathbf{S 1}$.

500

501 Our results demonstrated that the cytotoxicity of TPZ and its 502 complex was cell-, and time-dependent (Figure. 4A). C4-2B, an 503 androgen-independent ${ }^{34}$, derived bone metastatic PCa cell 504 model, exhibited high sensitivity to the hypoxia pro-drugs, with 505 clear dose-response shifts to the left at $1 \%$ hypoxia (Figure. S13). 506 The effect was especially pronounced in terms of hypoxia 507 selectivity, confirmed by the overall increased HCR values of $508 \mathrm{Cu}(\mathrm{TPZ})_{2}$, compared to TPZ (Table S1). The HCR values were 509 consistently higher for the complex and achieved exceptional 510 selectivity for this cell line at $72 \mathrm{~h}$ post-treatment (HCR: $72 \mathrm{~h}$, 511 70). Furthermore, the cytotoxic effects under normoxia 512 revealed a significant $2.03,2.61$ and 3.78-fold increase in $\mathrm{IC}_{50}$ (at 51348,72 and $96 \mathrm{~h}$, respectively) for $\mathrm{Cu}(\mathrm{TPZ})_{2}$ compared to TPZ 514 alone (Figure. 4A, top panel). More promisingly, enhanced 515 potentiation of the complex under hypoxia ( $\mathrm{IC}_{50}: 1.61 \pm 1.0$ ), 516 compared to TPZ (IC $\left.\mathrm{C}_{50}: 2.831 \pm 1.04 \mu \mathrm{M}\right)$ was also obtained at 72 $517 \mathrm{~h}$ time-point, confirming the augmented selectivity and 518 therapeutic potency of the complex in C4-2B. Similar finding 519 were obtained in LNCap, an androgen-dependent PC cells 520 (Figure. 4A, bottom panel), which showed high sensitivity to 521 both agents under hypoxia (Figure. S14), and superior hypoxia 522 selectivity with the $\mathrm{Cu}(\mathrm{TPZ})_{2}$ (Table S1). LNCap cells have been 523 shown to readapt under hypoxia, through a metabolic shift, 524 which may sensitize these cells to hypoxia-selective treatments $525^{35}$. It is therefore plausible to argue that oxygenation is only one 526 parameter influencing the activity of these drugs and may well 527 be a simplistic view of their MoA. All cell lines were cultured
528 under the same conditions, yet they exhibit differences in 529 toxicity and selectivity. Hypoxia adaptation and the reductive 530 capacity of these cell lines will certainly influence the sensitivity 531 to TPZ and $\mathrm{Cu}(\mathrm{TPZ})_{2}$.

532

\section{Potency of $\mathrm{Cu}(\mathrm{TPZ})_{2}$ against $\mathrm{C4}-2 \mathrm{~B}$ tumor spheroids}

534 In order to validate the previous cytotoxicity data in monolayers, $5353 \mathrm{D}$ hypoxia models of C4-2B, were developed (Figure. 5A \& 536 Figures. S15-S16), and C4-2B spheroids were incubated with TPZ 537 or $\mathrm{Cu}(\mathrm{TPZ})_{2}$ up to $96 \mathrm{~h}$. The resazurin assay was used to quantify 538 cell viability, and spheroids imaging was used to monitor cell 539 morphology post-treatment (Figure. S17). As expected, TPZ 540 (Figure 5B) was less potent in spheroids (Table S2) compared to 541 C4-2B monolayers (Table S1). Furthermore, TPZ toxicity in 3D 542 cultures was not dose- or time- dependent $\left(\mathrm{IC}_{50}\right.$ : $48 \mathrm{~h}, 35.17 \pm$ $5431.17 \mu \mathrm{M}$; 72h, $26.21 \pm 1.18 \mu \mathrm{M}$, 96h: $36.02 \pm 1.89 \mu \mathrm{M}$ ) (Figure. 544 5B \& Table S2). This data indicated that TPZ's toxicity is possibly 545 restricted to the spheroid surface layer, since it is metabolized 546 too rapidly $26,31,36-39$, as we previously showed. On the other 547 hand, $\mathrm{Cu}(\mathrm{TPZ})_{2}$ showed dose and time-dependent cytotoxicity in $548 \mathrm{C} 4-2 \mathrm{~B}$ spheroids (Figure $5 \mathrm{C}$ and Table S2) (IC $\mathrm{C}_{50}: 48 \mathrm{~h}, 41.78 \pm 5.67$ $549 \mu \mathrm{M} ; 72 \mathrm{~h}, 25.58 \pm 3.78 \mu \mathrm{M}, 96 \mathrm{~h}: 13.33 \pm 1.43 \mu \mathrm{M})$. The results 550 correlated well with the different metabolic rates of the 551 complex compared to TPZ (Figure. 3). At $48 \mathrm{~h}$, spheroids were 552 slightly more resistant to $\mathrm{Cu}(\mathrm{TPZ})_{2}\left(\mathrm{IC}_{50}: 41.78 \pm 5.67 \mu \mathrm{M}\right)$ 553 compared to TPZ $\left(\mathrm{IC}_{50}: 35.17 \pm 1.17 \mu \mathrm{M}\right)$, but reached a 554 pronounced therapeutic activity at $96 \mathrm{~h}\left(\mathrm{Cu}(\mathrm{TPZ})_{2}, \mathrm{IC}_{50}: 13.33 \pm\right.$ $5551.43 \mu \mathrm{M}$; TPZ, IC 50 : $36.02 \pm 1.89 \mu \mathrm{M}, \mathrm{p}<0.0001)$.

556

557 Furthermore, in order to determine the cellular responses 558 after TPZ and $\mathrm{Cu}(\mathrm{TPZ})_{2}$ drug testing, cell cycle and apoptosis 559 analyses were carried out. 5-days post seeding, C4-2B 560 spheroids were treated for $72 \mathrm{~h}$ with 20 and $2 \mu \mathrm{M}$ equivalent $561 \mathrm{TPZ}$ in both free and complex forms. Cell cycle histograms 562 were generated to evaluate cell cycle distribution (Figure. 563 s18). Interestingly, data showed marked arrest in S-phase 564 population, followed by decrease in $\mathrm{G} 1$ for $\mathrm{Cu}(\mathrm{TPZ})_{2}$ treated 565 spheroids at both $10(p<0.05)$ and $1 \mu \mathrm{M}(\mathrm{p}<0.01)$, compared to 566 untreated or TPZ-treated spheroids (Figure. 5D). Furthermore, 567 this significant S-phase arrest was accompanied by increased 568 propidium iodide (PI)-positive apoptotic cells following $\mathrm{Cu}(\mathrm{TPZ})_{2}$ $569(10 \mu \mathrm{M})$ treatment, compared to untreated and TPZ groups 570 (Figure. 5E).

\section{Enhanced DNA binding of $\mathrm{Cu}(\mathrm{TPZ})_{2}$}

572 The cell cycle analysis results suggested that TPZ cytotoxicity in 573 C4-2B spheroids may be mediated by non-selective 574 mitochondrial and ROS induced cell death ${ }^{40}$, while $\mathrm{Cu}(\mathrm{TPZ})_{2}$ may 575 exert an increased DNA selective cytotoxic activity. To confirm 576 the latter, UV-Vis absorption spectra of free TPZ were recorded 577 in the absence and presence of increasing concentrations of CT578 DNA solution (Figure. 5F). No spectral changes were observed, 579 indicating that TPZ did not interact with DNA in the absence of 580 its radical counterpart ${ }^{41}$. On the other hand, $\mathrm{Cu}(\mathrm{TPZ})_{2}$ (Figure. 581 5G) showed a significant hyperchromic effect in the entire 582 spectrum, with a small bathocromatic shift, which indicates a 583 non-intercalative binding mode through DNA groove binding, 584 resulting in damaging of the DNA double-helical structure ${ }^{25}$. The 585 DNA binding constant $\left(\mathrm{K}_{\mathrm{b}} 0.18 \times 10^{2} \mathrm{M}^{-1}\right)$ (Figure. 5G, inset), was 586 in agreement with other DNA groove binding agents and much 587 lower than standard DNA intercalators ${ }^{42}$. This indicates that $588 \mathrm{Cu}(\mathrm{TPZ})_{2}$ complex has a moderate DNA binding capacity, 
589 possibly through DNA groove binding, but intercalation cannot 590 be ruled out, supporting previous evidence on the enhanced 591 DNA damaging capacity of this complex ${ }^{21}$. Further studies on 592 DNA viscosity, damage and ROS production can further 593 elucidate the mechanisms of action of this cupric-TPZ complex.

\section{Discussion}

595 Cancer hypoxia has been highly associated with treatment 596 resistance and metastasis; therefore, a wide range of hypoxia597 activated prodrugs have been developed to targeting hypoxia ${ }^{1}$, $598^{2}$. TPZ is the most advanced bioreductive pro-drug in clinical 599 trials, however, its clinical efficacy has been limited by its poor 600 cellular uptake, restricted tissue diffusion and rapid metabolism $601{ }^{4}$. Several structure-activity relationship (SAR) studies with TPZ 602 analogues have provided substantive correlation between 603 specific substituents (and their position) with improved 604 pharmacological outcomes ${ }^{43}$. Moreover, the use of transition 605 metal complexes has shown to be a particularly suitable strategy 606 to modify existing pro-drugs and develop a new biologically 607 active molecule with improved hypoxia activity ${ }^{7}$. Copper(II) 608 complexes have shown to coordinate well with 1,2,4609 benzotriazine 1,4-di- $N$-oxides 44, 45, generating prodrug 610 complexes that are stable under physiological conditions, but 611 become kinetically labile with changes in the redox status or $\mathrm{pH}$ 612 of the environment. Two studies reported TPZ-copper complex 613 as a hypoxia-selective agent in 2D culture ${ }^{21,22}$, however, these 614 studies neither demonstrated any correlation between the 615 complex characteristics and its biological activity, nor assessed 616 its activity in 3D hypoxia culture models. In our work, we have 617 revealed unreported characteristics of the complex, such as its 618 lipophilicity (LogP 2.88), particulate nature, slow metabolism, as 619 well as its superior intrinsic fluorescence, enabling its cellular 620 trafficking and quantification under normaxia and hypoxia. 621 Collectively, with the published reductive potential of the 622 complex, we have been able, and for the first time, to provide 623 better understanding of the biological activity of the complex in 624 2D and 3D hypoxia PC models.

\section{5}

626 TPZ has been shown to possess a pH-dependent cytotoxicity ${ }^{46}$, 627 where the slightly acidic microenvironment $(\mathrm{pH} \quad 6.0)$ 628 dramatically increased its aerobic cytotoxicity, thus contributing 629 to the observed clinical side-effects (muscle cramping, 630 peripheral neuropathy, and intestinal symptoms) 4, 5 . 631 Interestingly, our results suggest that the high pH stability of the 632 complex could minimize TPZ systemic toxicity. Studies have also 633 shown that the reductive hypoxic environment plays a key role 634 in determining the dissociation rate of metal-complexes. 635 Previous reports have shown that copper trans-chelation could 636 occur with serum albumin 47 , or thiol-rich molecules 637 (glutathione, cysteine and ascorbate), which are capable of 638 reducing these complexes intracellularly ${ }^{27}$. The former was not 639 observed with our complex since high serum stability was 640 observed. Nevertheless, previous data ${ }^{21}$ showed that TPZ can 641 compete with glutathione for copper, but not EDTA, once again 642 confirming the stability of $\mathrm{Cu}(\mathrm{TPZ})_{2}$. All these findings are 643 important from a biological point of view, and the data 644 presented here suggested that $\mathrm{Cu}(\mathrm{TPZ})_{2}$ may be dissociated via 645 a pH-dependent mechanism, intracellular thiol-mediated 646 reduction, but not by serum albumin trans-chelation 647 emphasising its stability in the blood followings its systemic 648 administration.

649
650 Previous reports, have shown high potentiation of TPZ under 651 different hypoxia levels (HCR: 30-300) that was cell-line 652 dependent ${ }^{4}$. Factors such as p53 status, expression of reductive 653 enzymes, e.g. cytochrome c P450 48, CA-IX, acidic 654 microenvironment and of homologous recombination proteins 655 (XRCC2, Rad51D, BRCA1 and BRCA2) have been shown to 656 influence TPZ sensitivity and cannot be ruled out 48 . 657 Interestingly, the PC cell lines used here showed differential 658 metabolic profiles under hypoxia and aggressiveness is marked 659 by defects in DNA repair mechanisms, p53 status and increased 660 basal ROS levels ${ }^{35}$. Previously, Adsule et al. ${ }^{18}$, developed a 661 potent quinoline-2-carboxaldehyde copper complex, which 662 inhibited proteasome activity in PC-3 and LNCaP cells (IC So $_{50}$ of 663 and $3.2 \mu \mathrm{M}$, respectively). However, studies were only carried 664 out under normoxic conditions, not specifying any hypoxia 665 selectivity. In this work, $\mathrm{Cu}(\mathrm{TPZ})_{2}$ complex exhibited low 666 cytotoxicity under normoxia with $\mathrm{IC}_{50}$ above $c a$. $50 \mu \mathrm{M}$ for all cell 667 lines, while under $1 \%$ hypoxia $I C_{50}$ values ranged from moderate $668(>10 \mu \mathrm{M})$ to potent activity $(<10 \mu \mathrm{M})$. $\mathrm{Cu}(\mathrm{TPZ})_{2}$ showed higher 669 potency, compared to TPZ, in C4-2B, but higher selectivity was 670 observed in both cells tested. The HCR heatmap results 671 (Figure. 4B) showed a moderate effect at $48 \mathrm{~h}$, for both drugs, 672 against LNCap, and C4-2B. HCR values were consistently higher 673 for $\mathrm{Cu}(\mathrm{TPZ})_{2}(>10)$ in LNCap and C4-2B, compared to TPZ, with 674 outstanding selectivity in C4-2B after 72 h (HCR of $c a .70$ ), 675 confirming the potential of this complex as HAPs in PC. This 676 superior selectivity is attributed to the higher electronegativity 677 of the complex compared to TPZ. Most research surrounding 678 hypoxia selectivity is based on the unique cellular trapping 679 mechanism proposed for CU(ATSM) ${ }^{49}$. This copper(II) complex 680 has been widely exploited in vitro and in vivo, due to its 681 enhanced accumulation in hypoxic tissues. Generally, 682 complexes with reduction potential more electronegative than $6830.57 \mathrm{~V}$ vs. $\mathrm{Ag} / \mathrm{AgCl}$, display optimum hypoxia selectivity. Upon 684 reduction, under hypoxia, these copper(II) complexes will 685 partially dissociate into an intermediary copper(I) compound, 686 which is more labile and eventually undergoes complete 687 dissociation, liberating the free ligand ${ }^{50}$. Copper $(\mathrm{I})$ is then bound 688 to specific binding proteins and chaperones such as Ctr1 and 689 Atx1, respectively, which mediate the copper cellular pool 50 . 690 Whilst, under normoxia, the intermediary copper(I) compound 691 will be reversibly oxidize to its copper(II) counterpart and diffuse 692 out of the cells. Although the redox-properties provide reliable 693 gold-standard in hypoxia selectivity, other factors influencing 694 reduction rate should not be ruled out. Indeed, the degree of 695 expression of intracellular reductases has shown to influence 696 dissociation, as well as other biological reductants such as 697 ascorbate, thiols or NADP(H), as discussed previously.

698 TPZ's limited diffusion and incapacity to reach the relevant 699 hypoxic cells, in tumor models have been previously reported ${ }^{26}$, 700 31,36-39. To overcome these limitations, analogues with increased 701 lipophilicity (due to removal of $\mathrm{H}$-bond donor of the $3 \mathrm{NH}_{2}$ 702 group), comparable to that of $\mathrm{Cu}(\mathrm{TPZ})_{2}$, showed pronounced 703 uptake, selectivity and tissue diffusion, 26, 38, 43. In agreement 704 with these studies, the superior potency of the complex in C4705 2B spheroids, compared to free TPZ, as confirmed by cell 706 viability and cell cycle analysis, could be attributed to the high 707 lipophilicity of the complex in combination with its good $\mathrm{pH}$ and 708 serum stability, slow metabolism, and high electronegative 709 potential $(-0.75 \mathrm{~V})$, resulting in decreased early onset toxicity to 710 the outer layer of the spheroid and possible free ligand back- 
711 diffusion from the inner spheroid to induce high cell toxicity 712 throughout the spheroid environment ${ }^{51}$. Furthermore, its 713 higher DNA binding as we demonstrated, and reported by 714 others ${ }^{21}$ could contribute to higher potency. However, the 715 exact mechanism of toxicity in spheroids has yet to be 716 investigated.

\section{7}

\section{Conclusions}

719 We successfully presented the synthesis and extensive 720 characterization of a nano-sized $\mathrm{Cu}(\mathrm{TPZ})_{2}$ complex that 721 improved on TPZ's physicochemical properties and its hypoxia 722 selectivity in PC. The synthesized copper-complex, exhibited 723 high LogP, increased biocompatible redox-potential, slow 724 metabolism, and high DNA binding, compared to TPZ. The 725 intrinsic fluorescence of the complex enabled studying its 726 cellular uptake, concluding on its significant hypoxia selective 727 uptake and accumulation in the perinuclear area and in 728 intracellular vesicles. In addition, our results reported for the 729 first time the biological activity of $\mathrm{Cu}(\mathrm{TPZ})_{2}$ complex in 3D 730 hypoxia models. Interestingly, $\mathrm{Cu}(\mathrm{TPZ})_{2}$ complex exhibited 731 excellent hypoxia selectivity compared to TPZ, particularly in the 732 castrate-resistant C4-2B PC monolayers. Furthermore, the 733 improved structural activity of the complex correlated well with 734 its enhanced efficacy in C4-2B spheroids. Further studies are still 735 warranted to determine the $\mathrm{Cu}(\mathrm{TPZ})_{2}$ exact mechanism of action 736 in vitro. Finally, the limited solubility of the complex could be 737 overcome using clinically relevant delivery systems, such as 738 liposomes, to assess its therapeutic efficacy in vivo.

\section{9}

\section{Conflicts of interest}

741 There are no conflicts to declare.

\section{Acknowledgements}

743 Dr Al-Jamal is thankful for Prostate Cancer UK (CDF-12-002 744 Career Development Fellowship), and the Engineering and 745 Physical Sciences Research Council (EPSRC) 746 (EP/M008657/1) for their financial support; and the EPSRC 747 UK National Mass Spectrometry Facility at Swansea 748 University for the mass spectrometry analysis. Ms Vera 749 Silva is grateful for The University of East Anglia 750 (UEA)/School of Pharmacy, for funding her PhD study 751 (studentship ref. 100099479).

752

753

754

755

756

757

758

759

760

761

762

763

764

765

766

767
768

\section{Table of Content}

\section{$\mathrm{Cu}(\mathrm{TPZ})_{2}$ complex as a promising hypoxia} selective cytotoxin in prostate cancer
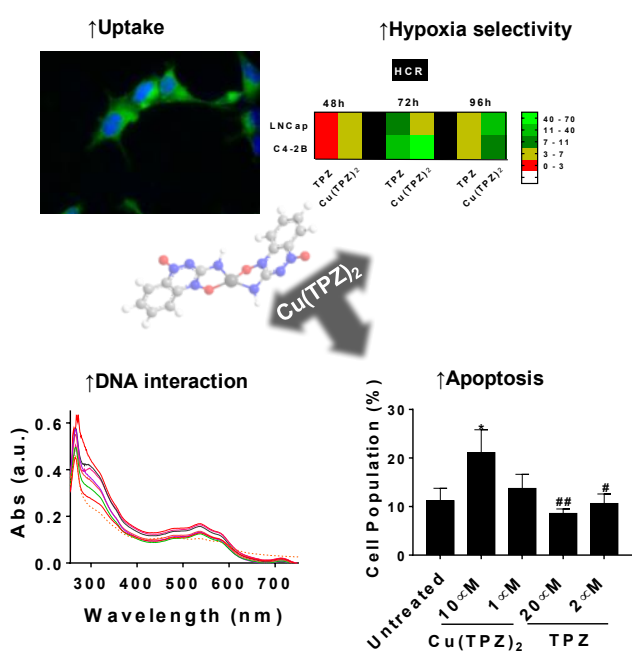

770

\section{References}

772 1. Denny, W. A., The role of hypoxia-activated prodrugs in cancer therapy. The 773 Lancet. Oncology 2000, 1 (1), 25-29.

774 2. Guise, C. P.; Mowday, A. M.; Ashoorzadeh, A.; Yuan, R.; Lin, W. H.; Wu, D. 775 H.; Smaill, J. B.; Patterson, A. V.; Ding, K., Bioreductive prodrugs as cancer 776 therapeutics: targeting tumor hypoxia. Chinese journal of cancer 2014, 33 (2), 8077786

778 3. Brown, J. M., SR 4233 (tirapazamine): a new anticancer drug exploiting 779 hypoxia in solid tumours. British journal of cancer 1993, 67 (6), 1163-1170. 780 4. Marcu, L.; Olver, I., Tirapazamine: from bench to clinical trials. Current 781 clinical pharmacology 2006, 1 (1), 71-79.

782 5. Reddy, S. B.; Williamson, S. K., Tirapazamine: a novel agent targeting hypoxic 783 tumor cells. Expert opinion on investigational drugs 2009, 18 (1), 77-87.

784 6. Kate, A. N.; Kumbhar, A. A.; Khan, A. A.; Joshi, P. V.; Puranik, V. G., 785 Monitoring Cellular Uptake and Cytotoxicity of Copper(II) Complex Using a 786 Fluorescent Anthracene Thiosemicarbazone Ligand. Bioconjugate Chemistry 787 2014, 25 (1), 102-114.

788 7. L. J. Dearling, J.; J. Blower, P., Redox-active metal complexes for imaging 789 hypoxic tissues: structure-activity relationships in copper(II)

790 bis(thiosemicarbazone) complexes. Chem Comm 1998, (22), 2531-2532.

$7918 . \quad$ Bergamo, A.; Dyson, P. J.; Sava, G., The mechanism of tumour cell death by 792 metal-based anticancer drugs is not only a matter of DNA interactions. Coord 793 Chem Rev 2018, 360, 17-33.

794 9. Blower, P. J.; Dilworth, J. R.; Maurer, R. I.; Mullen, G. D.; Reynolds, C. A.; 795 Zheng, Y., Towards new transition metal-based hypoxic selective agents for 796 therapy and imaging. Journal of inorganic biochemistry 2001, 85 (1), 15-22. 797 10. Dearling, J. L.; Lewis, J. S.; Mullen, G. E.; Rae, M. T.; Zweit, J.; Blower, P. J., 798 Design of hypoxia-targeting radiopharmaceuticals: selective uptake of copper-64 799 complexes in hypoxic cells in vitro. European journal of nuclear medicine 1998, 25 800 (7), 788-92.

801 11. Dearling, J. L.; Lewis, J. S.; Mullen, G. E.; Welch, M. J.; Blower, P. J., Copper 802 bis(thiosemicarbazone) complexes as hypoxia imaging agents: structure-activity 803 relationships. Journal of biological inorganic chemistry : JBIC : a publication of the 804 Society of Biological Inorganic Chemistry 2002, 7 (3), 249-59.

805 12. Santini, C.; Pellei, M.; Gandin, V.; Porchia, M.; Tisato, F.; Marzano, C.,

806 Advances in copper complexes as anticancer agents. Chemical reviews 2014, 114 807 (1), 815-62.

808 13. Knight, J. C.; Wuest, M.; Saad, F. A.; Wang, M.; Chapman, D. W.; Jans, H. 809 s.; Lapi, S. E.; Kariuki, B. M.; Amoroso, A. J.; Wuest, F., Synthesis,

810 characterisation and evaluation of a novel copper-64 complex with selective

811 uptake in EMT-6 cells under hypoxic conditions. Dalton Trans 2013, 42 (33),

812 12005-14.

813 14. Palanimuthu, D.; Shinde, S. V.; Somasundaram, K.; Samuelson, A. G., In

814 Vitro and in Vivo Anticancer Activity of Copper Bis(thiosemicarbazone)

815 Complexes. J Med Chem 2013, 56 (3), 722-734. 
816 15. Price, K. A.; Crouch, P. J.; Volitakis, I.; Paterson, B. M.; Lim, S.; Donnelly, P. 817 s.; White, A. R., Mechanisms controlling the cellular accumulation of copper 818 bis(thiosemicarbazonato) complexes. Inorganic chemistry 2011, 50 (19), 9594 819605.

820 16. Sandhaus, S.; Taylor, R.; Edwards, T.; Huddleston, A.; Wooten, Y.;

821 Venkatraman, R.; Weber, R. T.; González-Sarrías, A.; Martin, P. M.; Cagle, P.

822 Tse-Dinh, Y.-C.; Beebe, S. J.; Seeram, N.; Holder, A. A., A novel copper(II)

823 complex identified as a potent drug against colorectal and breast cancer cells and

824 as a poison inhibitor for human topoisomerase Il $\alpha$. Inorg Chem Comm 2016, 64,

825 45-49.

826 17. Zhang, Z.; Bi, C.; Schmitt, S. M.; Fan, Y.; Dong, L.; Zuo, J.; Dou, Q. P., 1,10-

827 Phenanthroline promotes copper complexes into tumor cells and induces

828 apoptosis by inhibiting the proteasome activity. Journal of biological inorganic

829 chemistry : JBIC : a publication of the Society of Biological Inorganic Chemistry

830 2012, $17(8), 1257-67$

831 18. Adsule, S.; Barve, V.; Chen, D.; Ahmed, F.; Dou, Q. P.; Padhye, S.; Sarkar,

832 F. H., Novel Schiff Base Copper Complexes of Quinoline-2 Carboxaldehyde as

833 Proteasome Inhibitors in Human Prostate Cancer Cells. J Med Chem 2006, 49

834 (24), 7242-7246.

835 19. Tardito, S.; Isella, C.; Medico, E.; Marchio, L.; Bevilacqua, E.; Hatzoglou,

836 M.; Bussolati, O.; Franchi-Gazzola, R., The thioxotriazole copper(II) complex A0

837 induces endoplasmic reticulum stress and paraptotic death in human cancer

838 cells. The Journal of biological chemistry 2009, 284 (36), 24306-19.

839 20. Stefani, C.; Al-Eisawi, Z.; Jansson, P. J.; Kalinowski, D. S.; Richardson, D. R.,

840 Identification of differential anti-neoplastic activity of copper

841 bis(thiosemicarbazones) that is mediated by intracellular reactive oxygen species

842 generation and lysosomal membrane permeabilization. Journal of inorganic

843 biochemistry 2015, 152 (Supplement C), 20-37.

844 21. Lin, P.-S.; Ho, K.-C., New cytotoxic mechanism of the bioreductive agent

845 Tirapazamine (SR 4233) mediated by forming complex with copper. Radiation

846 Oncology Investigations 1996, 4 (5), 211-220.

847 22. Lin, P. S.; Ho, K. C., CuTira brachytherapy: a new combination of radioactive

848 copper isotopes and the hypoxic cytotoxin, tirapazamine, for targeted tumor

849 therapy. Journal of nuclear medicine : official publication, Society of Nuclear

850 Medicine 1998, 39 (4), 677-8.

851 23. Sciences, E. L., ROS-ID ${ }^{\oplus}$ Hypoxia/Oxidative Stress Detection Kit. In Product

852 Manual.

853 24. Walzl, A.; Unger, C.; Kramer, N.; Unterleuthner, D.; Scherzer, M.;

854 Hengstschlager, M.; Schwanzer-Pfeiffer, D.; Dolznig, H., The Resazurin Reduction

855 Assay Can Distinguish Cytotoxic from Cytostatic Compounds in Spheroid

856 screening Assays. Journal of biomolecular screening 2014, 19 (7), 1047-59.

857 25. Meenongwa, A.; Brissos, R. F.; Soikum, C.; Chaveerach, P.; Gamez, P.;

858 Trongpanich, $Y$.; Chaveerach, U., DNA-interacting and biological properties of

859 copper(ii) complexes from amidino-O-methylurea. New Journal of Chemistry

860 2015, $39(1), 664-675$.

861 26. Hicks, K. O.; Siim, B. G.; Jaiswal, J. K.; Pruijn, F. B.; Fraser, A. M.; Patel, R.;

862 Hogg, A.; Liyanage, H. D.; Dorie, M. J.; Brown, J. M.; Denny, W. A.; Hay, M. P.;

863 Wilson, W. R., Pharmacokinetic/pharmacodynamic modeling identifies SN30000

864 and SN29751 as tirapazamine analogues with improved tissue penetration and

865 hypoxic cell killing in tumors. Clinical cancer research : an official journal of the

866 American Association for Cancer Research 2010, 16 (20), 4946-57.

867 27. Dux, E. L. The Development Of Transition Metal Complexes To Target

868 Hypoxic Cells. Doctoral Thesis, University of York, 2011.

869 28. Ko, K. C.; Wu, J.-S.; Kim, H. J.; Kwon, P. S.; Kim, J. W.; Bartsch, R. A.; Lee, J.

870 Y.; Kim, J. S., Rationally designed fluorescence 'turn-on' sensor for Cu2+. Chem

$871 \mathrm{comm} 2011,47(11), 3165-3167$.

872 29. Valderrama-Negrón, A. C.; Alves, W. A.; Cruz, Á. S.; Rogero, S. O.; de

873 Oliveira Silva, D., Synthesis, spectroscopic characterization and radiosensitizing

874 properties of acetato-bridged copper(II) complexes with 5-nitroimidazole drugs.

875 Inorganica Chimica Acta 2011, 367 (1), 85-92.

876 30. Poole, J. S.; Hadad, C. M.; Platz, M. S.; Fredin, Z. P.; Pickard, L.; Guerrero,

877 E. L.; Kessler, M.; Chowdhury, G.; Kotandeniya, D.; Gates, K. S., Photochemical

878 electron transfer reactions of tirapazamine. Photochemistry and photobiology

879 2002, 75 (4), 339-45

880 31. Hicks, K. O.; Pruijn, F. B.; Sturman, J. R.; Denny, W. A.; Wilson, W. R.,

881 Multicellular resistance to tirapazamine is due to restricted extravascular

882 transport: a pharmacokinetic/pharmacodynamic study in $\mathrm{HT} 29$ multicellular layer

883 cultures. Cancer research 2003, 63 (18), 5970-7.

884 32. Zagorevskii, D.; Song, M.; Breneman, C.; Yuan, Y.; Fuchs, T.; Gates, K. S.;

885 Greenlief, C. M., A mass spectrometry study of tirapazamine and its metabolites:

886 Insights into the mechanism of metabolic transformations and the

887 characterization of reaction intermediates. J Am Chem Soc Mass Spec 2003, 14

888 (8), 881-892.
889 33. Birincioglu, M.; Jaruga, P.; Chowdhury, G.; Rodriguez, H.; Dizdaroglu, M.; 890 Gates, K. S., DNA Base Damage by the Antitumor Agent 3-Amino-1,2,4-

891 benzotriazine 1,4-Dioxide (Tirapazamine). Journal of the American Chemical

892 Society 2003, $125(38), 11607-11615$.

893 34. Lin, D. L.; Tarnowski, C. P.; Zhang, J.; Dai, J.; Rohn, E.; Patel, A. H.; Morris,

894 M. D.; Keller, E. T., Bone metastatic LNCaP-derivative C4-2B prostate cancer cell

895 line mineralizes in vitro. The Prostate 2001, 47 (3), 212-221.

896 35. Higgins, L. H.; Withers, H. G.; Garbens, A.; Love, H. D.; Magnoni, L.;

897 Hayward, S. W.; Moyes, C. D., Hypoxia and the metabolic phenotype of prostate 898 cancer cells. Biochimica et biophysica acta 2009, 1787 (12), 1433-43.

899 36. Durand, R. E.; Olive, P. L., Evaluation of bioreductive drugs in multicell

900 spheroids. International journal of radiation oncology, biology, physics 1992, 22

901 (4), 689-692.

902 37. Hicks, K. O.; Fleming, Y.; Siim, B. G.; Koch, C. J.; Wilson, W. R., Extravascular

903 diffusion of tirapazamine: effect of metabolic consumption assessed using the

904 multicellular layer model. International journal of radiation oncology, biology,

905 physics 1998, 42 (3), 641-649.

906 38. Monge, A.; Palop, J. A.; de Cerain, A. L.; Senador, V.; Martinez, F. J.; Sainz,

907 Y.; Narro, S.; Garcia, E.; de Miguel, C., Hypoxia-Selective Agents Derived from

908 Quinoxaline 1,4-Di-N-oxides. J Med Chem 1995, 38 (10), 1786-1792.

909 39. Kyle, A. H.; Minchinton, A. I., Measurement of delivery and metabolism of

910 tirapazamine to tumour tissue using the multilayered cell culture model. Cancer

911 Chemotherapy and Pharmacology 1999, 43 (3), 213-220.

912 40. Wouters, B. G.; Delahoussaye, Y. M.; Evans, J. W.; Birrell, G. W.; Dorie, M.

913 J.; Wang, J.; MacDermed, D.; Chiu, R. K.; Brown, J. M., Mitochondrial

914 Dysfunction after Aerobic Exposure to the Hypoxic Cytotoxin Tirapazamine.

915 Cancer research 2001, 61 (1), 145-152.

916 41. Delahoussaye, Y. M.; Hay, M. P.; Pruijn, F. B.; Denny, W. A.; Brown, J. M.,

917 Improved potency of the hypoxic cytotoxin tirapazamine by DNA-targeting.

918 Biochemical pharmacology 2003, 65 (11), 1807-15.

919 42. Kathiresan, S.; Mugesh, S.; Murugan, M.; Ahamed, F.; Annaraj, J., Mixed-

920 ligand copper(ii)-phenolate complexes: structure and studies on DNA/protein

921 binding profiles, DNA cleavage, molecular docking and cytotoxicity. RSC Advances

922 2016, 6 (3), 1810-1825.

923 43. Hay, M. P.; Gamage, S. A.; Kovacs, M. S.; Pruijn, F. B.; Anderson, R. F.;

924 Patterson, A. V.; Wilson, W. R.; Brown, J. M.; Denny, W. A., Structure-activity

925 relationships of 1,2,4-benzotriazine 1,4-dioxides as hypoxia-selective analogues

926 of tirapazamine. J Med Chem 2003, 46 (1), 169-82.

927 44. Torre, M. H.; Gambino, D.; Araujo, J.; Cerecetto, H.; Gonzalez, M.; Lavaggi,

928 M. L.; Azqueta, A.; Lopez de Cerain, A.; Vega, A. M.; Abram, U.; Costa-Filho, A.

929 J., Novel Cu(II) quinoxaline N1,N4-dioxide complexes as selective hypoxic

930 cytotoxins. European journal of medicinal chemistry 2005, 40 (5), 473-80.

931 45. Urquiola, C.; Gambino, D.; Cabrera, M.; Lavaggi, M. L.; Cerecetto, H.;

932 González, M.; de Cerain, A. L.; Monge, A.; Costa-Filho, A. J.; Torre, M. H., New

933 copper-based complexes with quinoxaline N1,N4-dioxide derivatives, potential

934 antitumoral agents. Journal of inorganic biochemistry 2008, 102 (1), 119-126.

935 46. Skarsgard, L. D.; Skwarchuk, M. W.; Vinczan, A.; Chaplin, D. J., The effect of

$936 \mathrm{pH}$ on the aerobic and hypoxic cytotoxicity of SR4233 in HT-29 cells. British

937 journal of cancer 1993, 68 (4), 681-3.

938 47. Kheirolomoom, A.; Mahakian, L. M.; Lai, C.-Y.; Lindfors, H. A.; Seo, J. W.

939 Paoli, E. E.; Watson, K. D.; Haynam, E. M.; Ingham, E. S.; Xing, L.; Cheng, R. H.;

940 Borowsky, A. D.; Cardiff, R. D.; Ferrara, K. W., Copper-doxorubicin as a

941 nanoparticle cargo retains efficacy with minimal toxicity. Mol pharm 2010, 7 (6)

942 1948-1958.

943 48. Delahoussaye, Y. M.; Evans, J. W.; Brown, J. M., Metabolism of tirapazamine

944 by multiple reductases in the nucleus. Biochemical pharmacology 2001, 62 (9),

945 1201-9.

946 49. Holland, J. P.; Lewis, J. S.; Dehdashti, F., Assessing tumor hypoxia by

947 positron emission tomography with Cu-ATSM. Q J Nucl Med Mol Imaging 2009,

$94853(2), 193-200$.

949 50. Xiao, Z.; Donnelly, P. S.; Zimmermann, M.; Wedd, A. G., Transfer of copper

950 between bis(thiosemicarbazone) ligands and intracellular copper-binding

951 proteins. insights into mechanisms of copper uptake and hypoxia selectivity.

952 Inorganic chemistry 2008, 47 (10), 4338-47.

953 51. Wilson, W. R.; Moselen, J. W.; Cliffe, S.; Denny, W. A.; Ware, D. C.,

954 Exploiting tumor hypoxia through bioreductive release of diffusible cytotoxins:

955 The cobalt(III)-nitrogen mustard complex SN 24771. International journal of

956 radiation oncology, biology, physics 1994, 29 (2), 323-327.

957

958 


\section{Figures and captions}<smiles>Nc1n[n+]([O-])c2ccccc2[n+]1[O-]</smiles>

TPZ

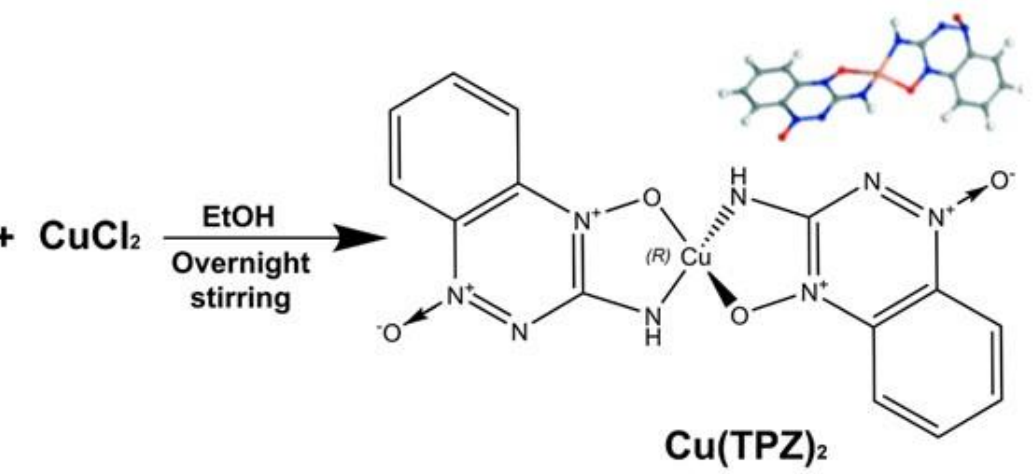

C

\begin{tabular}{|c|c|c|}
\hline Property & TPZ & $\mathrm{Cu}(\mathrm{TPZ})_{2}$ \\
\hline $\mathrm{MW}(\mathrm{g} / \mathrm{mol})$ & 179.15 & 417.83 \\
\hline pKa & $5.6^{a}$ & 2.7 \\
\hline $\log P$ & $-0.31^{a}$ & $2.88^{*}$ \\
\hline$E_{\text {red }}(1)(V)^{* *}$ & $-0.65^{a}$ & $-0.75^{b}$ \\
\hline \multicolumn{3}{|c|}{$\begin{array}{l}\text { afrom reference [5]] } \\
\text { bfrom reference [47] } \\
\text { ing Chemdraw } 3 \mathrm{D} 15.0 \\
\text { ence electrode Ag/AgCl }\end{array}$} \\
\hline [ & DMSO & \\
\hline
\end{tabular}
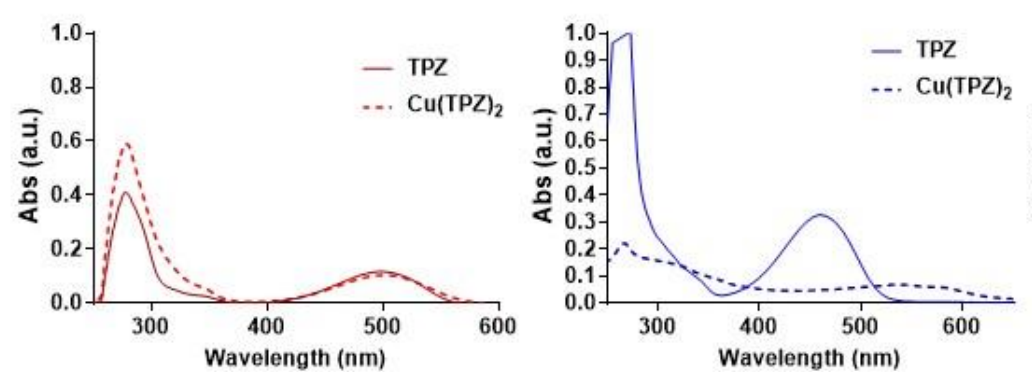

$20 \mu \mathrm{M}$

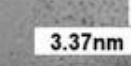

$3.63 \mathrm{~nm}$

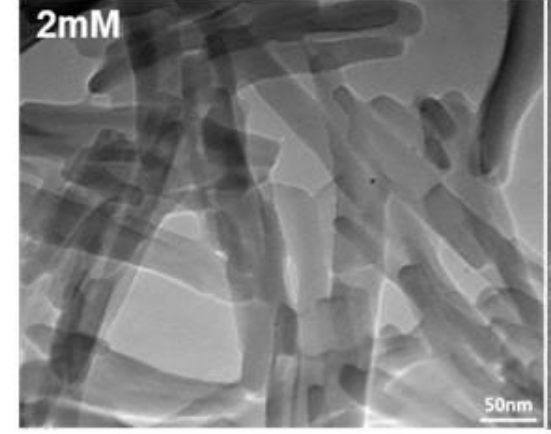

\section{$3.32 \mathrm{~nm}$}

Figure 1. Synthesis and characterization of hypoxia-selective $\mathrm{Cu}(\mathrm{TPZ})_{2}$ complex. A) Schematic representation of the synthesis protocol of $\mathrm{Cu}(\mathrm{TPZ})_{2}$ complex in ethanol (Inset: optimised structure); B) A summary of main physicochemical properties of TPZ and $\left.\mathrm{Cu}(\mathrm{TPZ})_{2} ; \mathrm{C}\right)$ TEM images of $\mathrm{Cu}(\mathrm{TPZ})_{2}$ at high $(2 \mathrm{mM})$ and low $(20 \mu \mathrm{M})$ concentrations, depicting a concentration-dependent, self-aggregation of the complex in ethanol; D) Absorbance spectra of TPZ (10 $\mu \mathrm{M}$, solid line) and Cu(TPZ) 2 (5 $\mu \mathrm{M}$, dotted line) in DMSO; E) Absorbance spectra of TPZ (60 $\mathrm{MM}$, solid line) and $\mathrm{Cu}(\mathrm{TPZ})_{2}$ (30 $\mu \mathrm{M}$, dotted line) in HBS; and F) Absorbance of $\mathrm{Cu}(\mathrm{TPZ})_{2}(50 \mu \mathrm{M})$ at different $\mathrm{pH}$ values, illustrating a $\mathrm{pH}$-dependent dissociation of $\mathrm{Cu}(\mathrm{TPZ})_{2}$. Inset shows a yellow color change of TPZ to a dark red solution upon complexation and vice-versa, upon dissociation. 
A
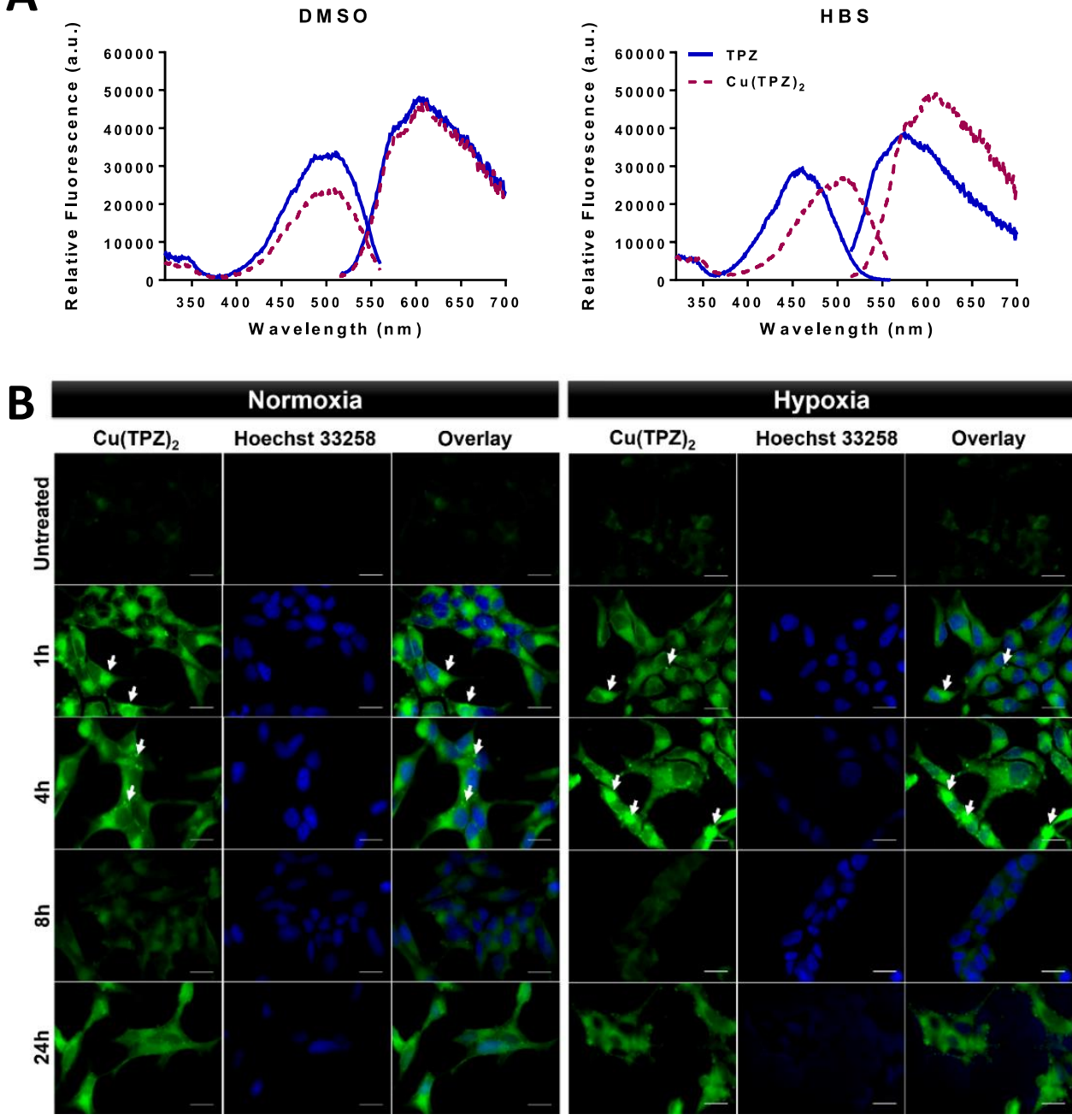

C

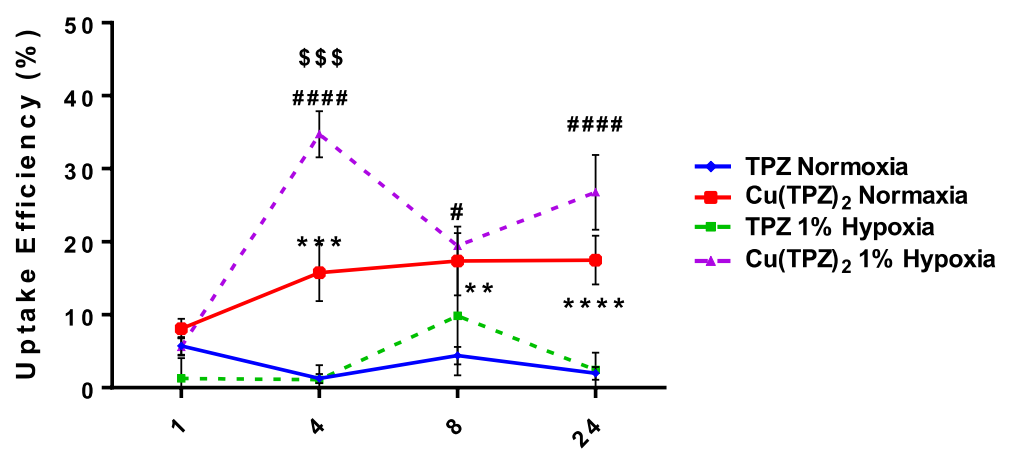

Time (h) 
Figure 2. Intrinsic fluorescence, uptake and cellular localization of $\mathrm{Cu}(\mathrm{TPZ})_{2}$ complex in $\mathrm{C} 4-2 \mathrm{~B}$ prostate cancer cells. A) Fluorescence spectra of TPZ and Cu(TPZ) 2 diluted in DMSO (left) and HBS (right) (DMSO: $\lambda_{\text {exc }} / \lambda_{\text {em }} 490 / 600 \mathrm{~nm} ; \mathrm{HBS}: \lambda_{\text {exc }} / \lambda_{\text {em }}$ $450 / 570 \mathrm{~nm}(\mathrm{TPZ})$ and $\lambda_{\text {exc }} / \lambda_{\text {em }} 500 / 600 \mathrm{~nm}\left(\mathrm{Cu}(\mathrm{TPZ})_{2}\right)$. B) Qualitative uptake of $\mathrm{Cu}(\mathrm{TPZ})_{2}(100 \mu \mathrm{M}$ equivalent TPZ) at $1,4,8$ and $24 \mathrm{~h}$ under normoxia and $1 \%$ hypoxia. The white arrows depict intense green puncta signals, suggesting accumulation of the complex in intracellular vesicles. The signals were more prominent under hypoxic conditions and in the perinuclear area. Images are representative of at least 50 cells of two independent experiments $(n=2)$. Green channel: $\mathrm{Cu}(T P Z)_{2}$ treated cells; Blue channel: nuclei stained with Hoechst 33258. Scale bars, $20 \mu \mathrm{m}$. C) Quantitative uptake of TPZ and Cu(TPZ) 2 in C4-2B cells. Cells were incubated with $25 \mu \mathrm{M}$ equivalent TPZ, and the cellular uptake was determined at 1, 4, 8 and $24 \mathrm{~h}$ under normoxia and $1 \%$ hypoxia. Fluorescence was measured at $\lambda_{\text {exc }} / \lambda_{\mathrm{em}} 485 / 590 \mathrm{~nm}$ in DMSO. Results were expressed as mean \pm SD for triplicates of three independent experiments $(n=3)$. Statistical analysis using Two-way ANOVA multiple comparison with Bonferroni Post-test (GraphPad Prism version 7.0, GraphPad Software Inc., La Jolla, CA, USA) was performed to compare uptake

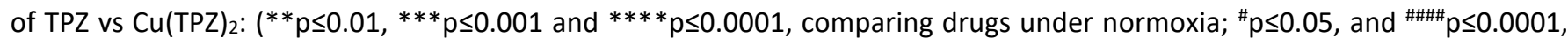
comparing drugs under hypoxia; and ${ }^{\$ \$} \mathrm{p} \leq 0.001$, comparing $\mathrm{Cu}(\mathrm{TPZ})_{2}$ under hypoxia and normoxia. 

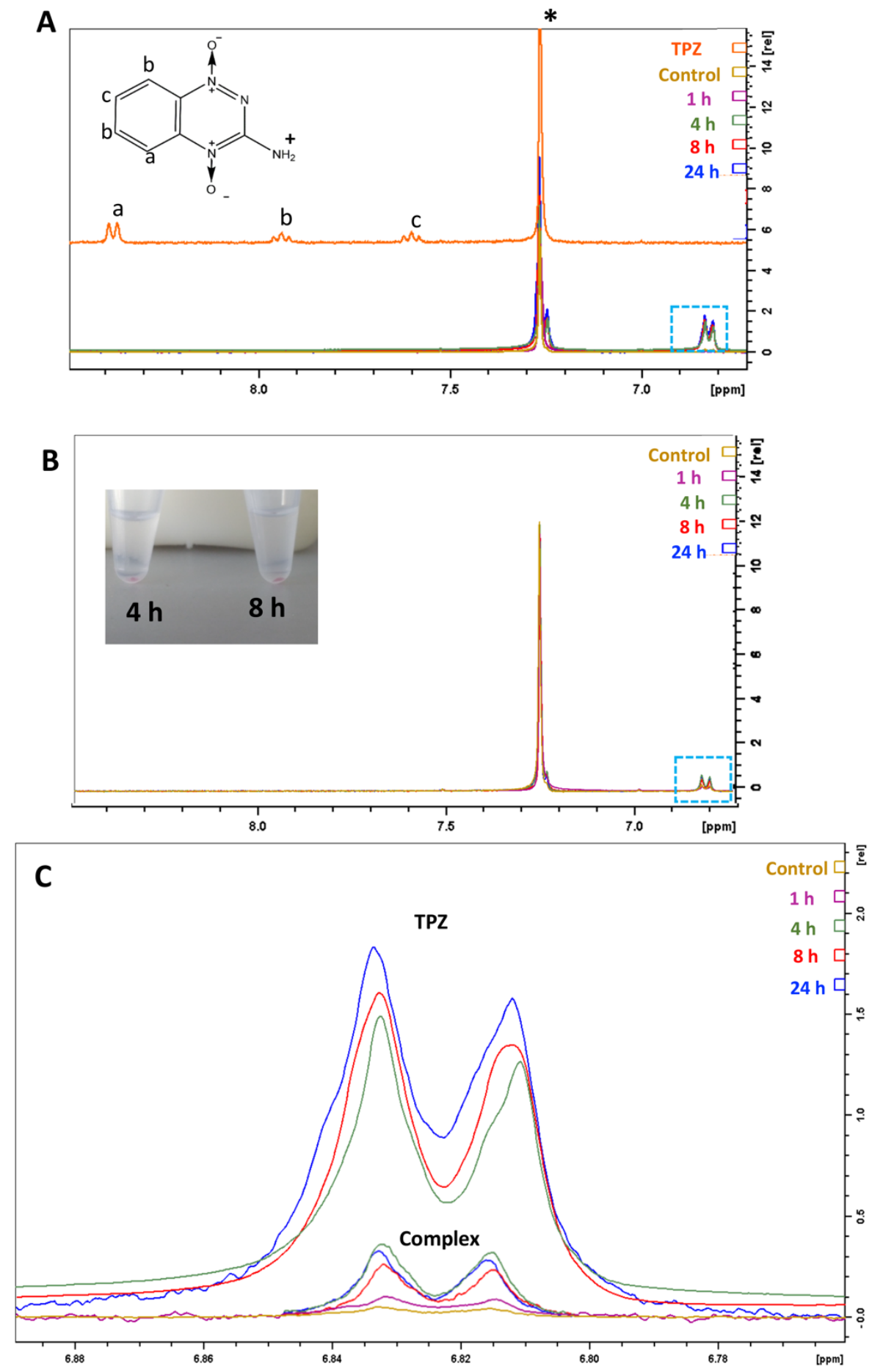

Figure 3: ${ }^{1} \mathrm{H}-\mathrm{NMR}$ in $\mathrm{CDCl}_{3}$ of $\mathrm{C4}-2 \mathrm{~B}$ cell lysates. Cells were incubated under $1 \%$ hypoxia with (A) TPZ and (B) $\mathrm{Cu}(\mathrm{TPZ})_{2}$ for different duration $(1,4,8,24 \mathrm{~h})$. Untreated cells were used as a control. Samples were prepared for NMR analysis as described in the methods section. TPZ (1 mg/ $400 \mu \mathrm{l})$ was also analysed (peaks a,b,c), however the complex was not soluble in $\mathrm{CDCl}_{3}$ and no peaks were detected. The photograph (inset in Figure. 3B) represents the pinkish cell lysate pellets, indicating the presence of $\mathrm{Cu}(\mathrm{TPZ})_{2}$ in the cell lysate samples. The main sharp peak $\left({ }^{*}\right)$ represents the solvent. (C) peak heights for the TPZ and $\mathrm{Cu}(\mathrm{TPZ})_{2}$ metabolites. 
A
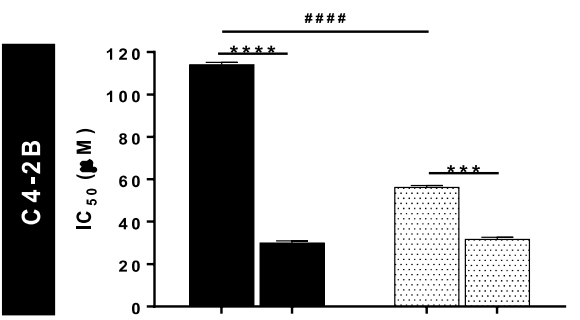

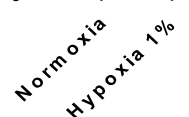

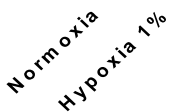

2

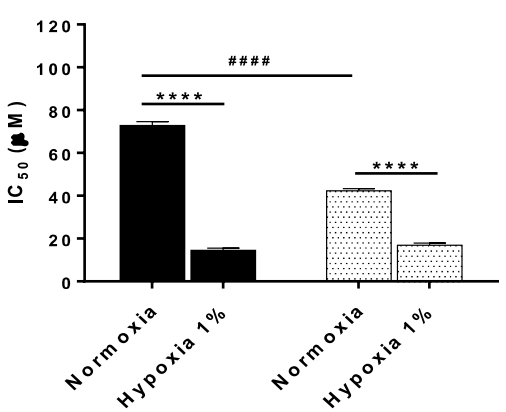

B
$72 \mathrm{~h}$
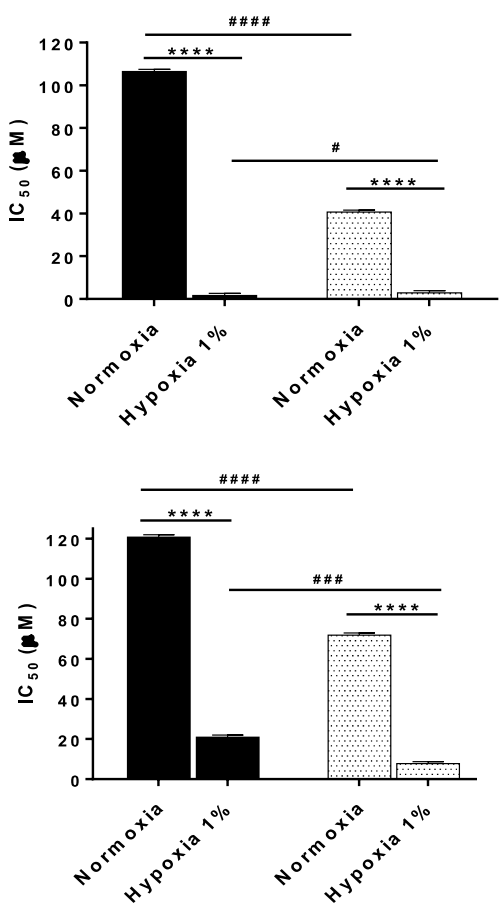

\section{HCR}

$96 \mathrm{~h}$
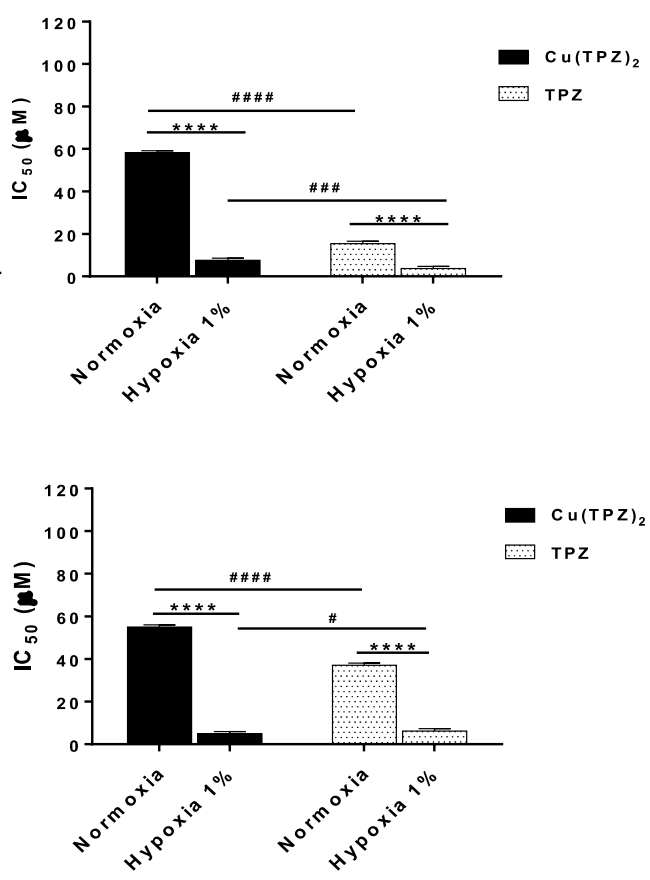

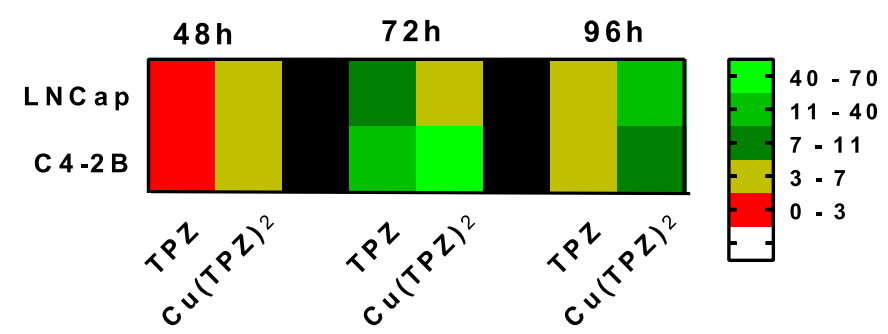

Figure 4. $I C_{50}$ values of $\mathrm{Cu}(\mathrm{TPZ})_{2}$ complex and TPZ incubated with two PCa cells under normoxia and 1\% hypoxia. A) C4-2B (top panel) and LNCap (bottom panel) cells were incubated under normoxia and $1 \%$ hypoxia with equivalent doses of Cu(TPZ) 2 and TPZ, and $\mathrm{IC}_{50}$ values were determined after 48,72 and $96 \mathrm{~h}$ of incubation; B) Heat map of the hypoxia cytotoxicity ratio (HCR) values obtained for TPZ and $\mathrm{Cu}(T P Z)_{2}$ in the two PCa cell lines studied above. The IC 50 values for inhibition were assessed by the resazurin assay and determined by nonlinear regression analysis of the data fit to a four-parameter equation (GraphPad Prism version 7.0, GraphPad Software Inc., La Jolla, CA, USA) and used to calculate HCR: IC 50 normoxia/IC 50 hypoxia. Results are expressed as mean \pm SD for six replicates of at least three independent experiments $(n>3)$. Statistical analysis: Two-way ANOVA multiple comparison Bonferroni Post-hoc test $(* * * p \leq 0.001$ and $* * * * p \leq 0.0001$, comparing normoxia vs hypoxia; \#p $\leq 0.05$, $\# \# \#$ $\leq 0.001$ and \#\#\#\#p $\leq 0.0001$, comparing $\mathrm{Cu}(\mathrm{TPZ})_{2}$ vs TPZ). 
A

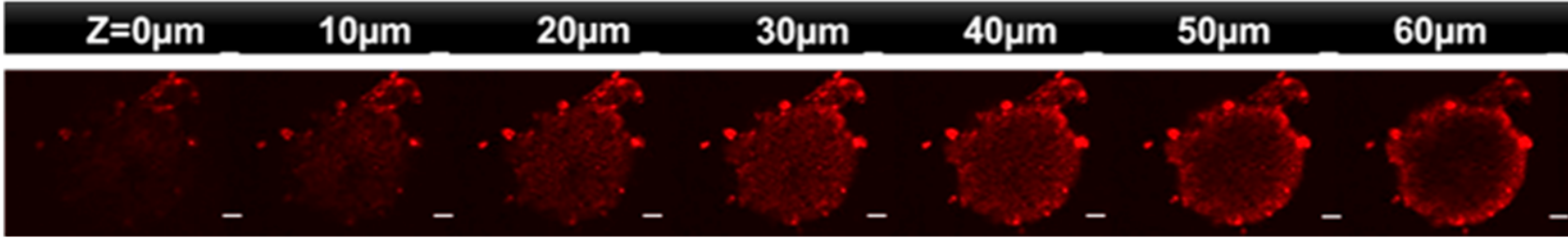

B

TPZ

C

$\mathrm{Cu}(\mathrm{TPZ})_{2}$
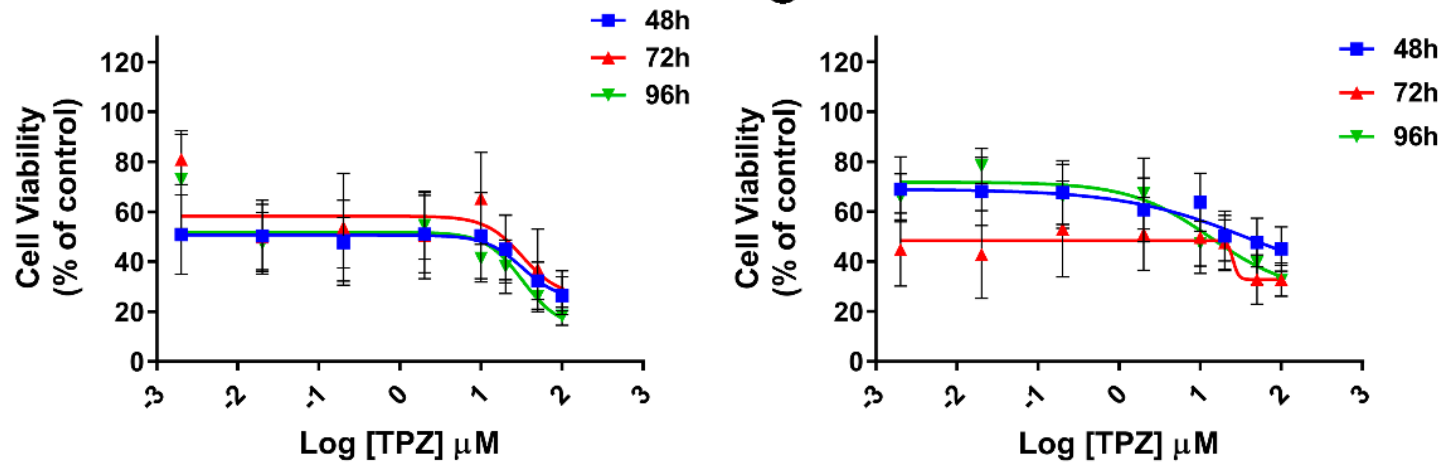

TPZ vs $\mathrm{Cu}(\mathrm{TPZ})_{2}$

D
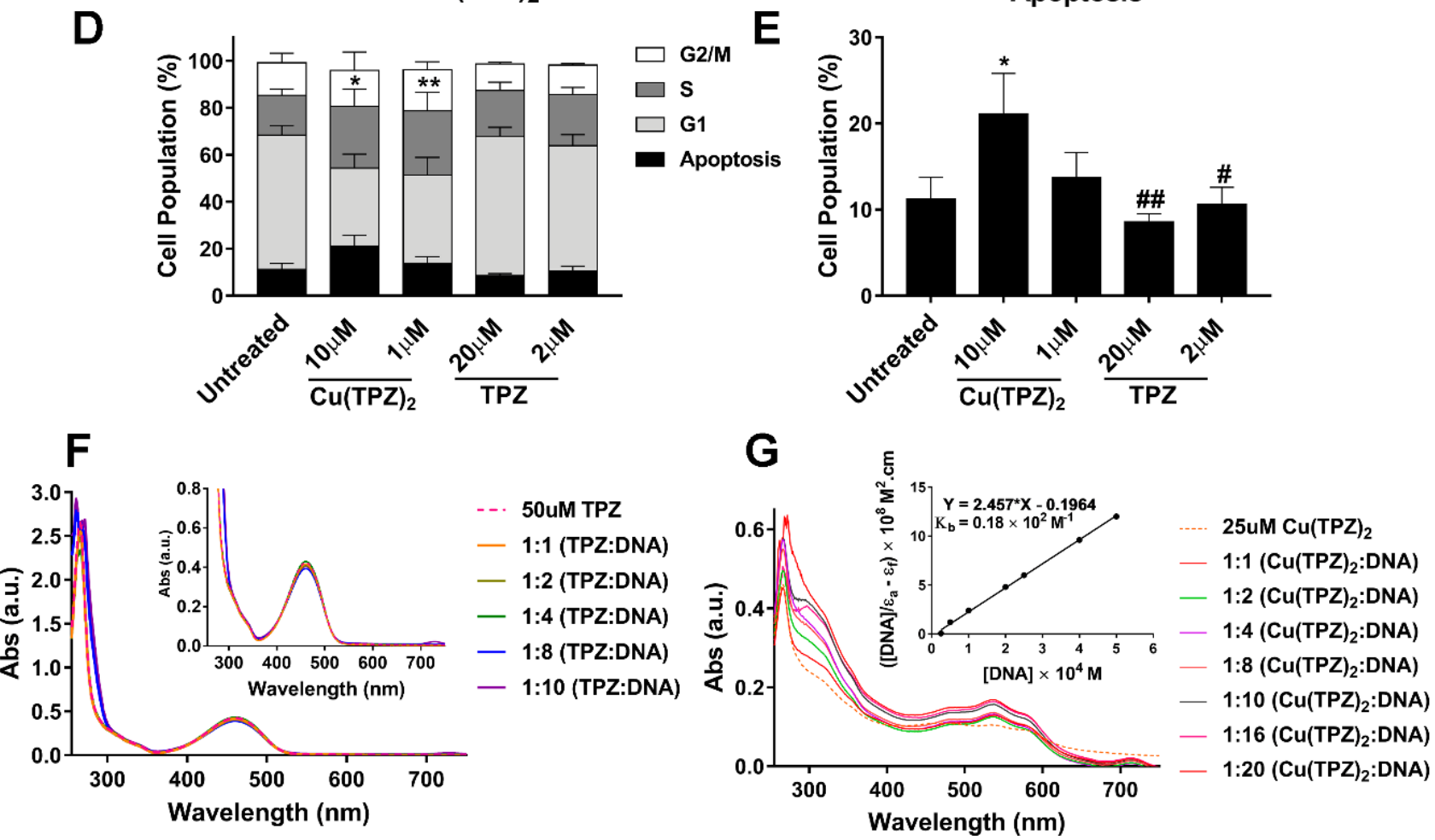

Figure 5. In vitro toxicity of $\mathrm{Cu}(\mathrm{TPZ})_{2}$ in C4-2B spheroids and DNA binding assay. A) fluorescent images of 3D C4-2B spheroids (day 5) incubated with CYTO-ID ${ }^{\circledR}$ Hypoxia Detection probe (500 nM, Enzo Life Sciences. UK) for 4 h, taken using an inverted Zeiss Axiovert 200M with Texas Red (596/670 nm) filter and equipped with a Zeiss ApoTome (Carl Zeiss, UK) to create optical sections free of scattered light. For each spheroid, a Z-stack with $10 \mu \mathrm{m}$ thickness was generated. Scale bar: $100 \mu \mathrm{m}$. IC 50 curves of B) TPZ and C) $\mathrm{Cu}(\mathrm{TPZ})_{2}$ in C4-2B spheroids. 5 days post seeding, tumor spheroids were incubated with equivalent doses of $\mathrm{Cu}(\mathrm{TPZ})_{2}$ and TPZ, and IC 50 values were determined after 48, 72 and $96 \mathrm{~h}$. Cell viability was assessed by the resazurin assay, with spheroids pre-treated for $30 \mathrm{~min}$ with EDTA $(5 \mathrm{mM})$. Results were normalized to untreated and expressed as mean \pm SD for six replicates of at least two independent experiments $(n \geq 2)$. The $I C_{50}$ values for inhibition were determined by nonlinear 
regression analysis of the data fit to a four-parameter equation (GraphPad Prism version 7.0, GraphPad Software Inc., La Jolla, CA, USA). C4-2B spheroids were cultured for 5 days, then treated for $72 \mathrm{~h}$ with 20 and $2 \mu \mathrm{M}$ equivalent TPZ in both free and complex forms and analyzed for $\mathrm{D}$ ) cell cycle distribution and $\mathrm{E}$ ) the percentage of apoptotic cells. Each flow cytometry plot depicts the mean \pm SD percentage of $G 1(2 n)$, S and G2/M (4n) fraction population. The data represents the mean of at least ten pooled spheroids of two independent experiments ( $n=2)$. F) Absorption spectra of the TPZ (50 $\mu M)$ in the absence (dashed line) and presence (solid line) of increasing amounts of CT-DNA at room temperature in $5 \mathrm{mM} \mathrm{Tris/HCl} / 50 \mathrm{mM} \mathrm{NaCl} \mathrm{buffer,} \mathrm{PH}$ 7.2. Inset shows a zoom in of the visible spectral region, showing no changes in the spectrum. G) Absorption spectra of the complex $(25 \mu \mathrm{M})$ in the absence (dashed line) and presence (solid line) of increasing amounts of CT-DNA at room temperature in $5 \mathrm{mM}$ Tris/ $\mathrm{HCl} / 50 \mathrm{mM} \mathrm{NaCl}$ buffer, $\mathrm{pH}$ 7.2. The arrow depicts the absorbance spectrum changes on increasing the CT-DNA concentration. Inset shows the plot of [DNA]/( $\left.\varepsilon_{a}-\varepsilon_{f}\right) /\left(\varepsilon_{b}-\varepsilon_{f}\right)$ vs [DNA] and derived $K_{b}$ value $\left(M^{-1}\right)$; Statistical analysis: Two-way ANOVA multiple comparison Bonferroni Post-hoc test $\left({ }^{*} p<0.05{ }^{*} p<0.01\right.$, compared to control and ${ }^{*} p<0.05{ }^{*} p<0.01$, comparing TPZ vs $\mathrm{Cu}(\mathrm{TPZ})_{2}$, GraphPad Prism version 7.0). 